\title{
Southern Hemisphere Origins for Interannual Variations of Snow Cover over the Western Tibetan Plateau in Boreal Summer
}

\author{
JUAN DOU \\ Earth System Modeling Center, Nanjing University of Information Science and Technology, Nanjing, and \\ Institute of Atmospheric Sciences, Fudan University, Shanghai, China \\ ZHIWEI WU \\ Institute of Atmospheric Sciences, Fudan University, Shanghai, China
}

(Manuscript received 18 May 2017, in final form 18 June 2018)

\begin{abstract}
The climate response to the Tibetan Plateau (TP) snow cover (TPSC) has been receiving extensive concern. However, relatively few studies have been devoted to revealing the potential factors that can contribute to the TPSC interannual variability, especially during boreal summer. This study finds that the May Southern Hemisphere (SH) annular mode (SAM), the dominating mode of atmospheric circulation variability in the SH extratropics, exhibits a significant positive relationship with the interannual variations in western TPSC during boreal summer. Observational analysis and numerical experiments manifest that the signal of the May SAM can be "prolonged" by a meridional Indian Ocean tripole (IOT) sea surface temperature anomaly (SSTA) via atmosphere-ocean interaction. The IOT SSTA pattern persists into the following summer and excites anomalous local-scale zonal-vertical circulation. Subsequently, a tropical dipole rainfall (TDR) mode is induced with precipitation anomalies between the tropical western Indian Ocean and the eastern Indian Ocean-Maritime Continent. Rossby wave ray tracing diagnosis reveals that the wave energies, generated by the latent heat release of the TDR mode, can propagate northward into the western TP. As a response, abnormal cyclone (or anticyclone) and upward (or downward) movement are triggered over the western TP, providing favorable dynamical conditions for more (or less) TPSC. Moreover, the strong May SAM is usually followed by a cold air temperature anomaly over the western TP in summer, which is unfavorable for snow-cover melting, and vice versa. In brief, the IOT SSTA plays an "ocean bridge" role and the TDR mode plays an "atmosphere bridge" role in the process of the May SAM impacting the following summer TPSC variability. The results may provide new insight into the cross-equatorial propagation of the SAM influence.
\end{abstract}

\section{Introduction}

As the third pole of Earth, the Tibetan Plateau (TP) is a huge cooling source in the midtroposphere in the cold seasons and a tremendous heating source in the warm seasons (Yeh et al. 1957; Ye and Wu 1998). TP snow cover (TPSC) greatly affects the thermal characteristics of the plateau through its high albedo and low thermal conductivity (Luo and Yanai 1984; Namias 1985; Cohen and Rind 1991; Xu and Dirmeyer 2013), and then exerts a huge influence on the global and regional climate change (e.g., Barnett et al. 1988, 1989; Yasunari et al. 1991; Zhao and Moore 2004; Lin

Corresponding author: Prof. Zhiwei Wu, zhiweiwu@fudan.edu.cn and $\mathrm{Wu} 2011,2012)$. The potential impact of TPSC variability on remote climate anomalies, especially during winter and spring, has been studied extensively (e.g., Bamzai and Shukla 1999; Bamzai and Marx 2000; Qian et al. 2003; Zhang et al. 2004; Zhao et al. 2007; Zhu et al. 2015; Wang et al. 2017; Xiao and Duan 2016).

However, a comparatively small number of studies have concentrated on the boreal summer TPSC variability and its climatic effects. Actually, snow cover can be sustained during boreal summer over the western and southern edge of the TP where there are large mountain ridges and it shows a strong interannual variation $(\mathrm{Pu}$ et al. 2007; Liu et al. 2014a; $\mathrm{Wu}$ et al. 2016a). Although snow cover in summer 
a) Climatology of JJA TPSC

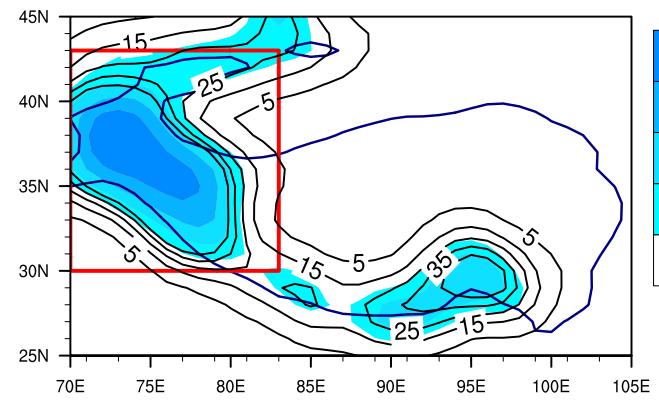

c) ENSO removed

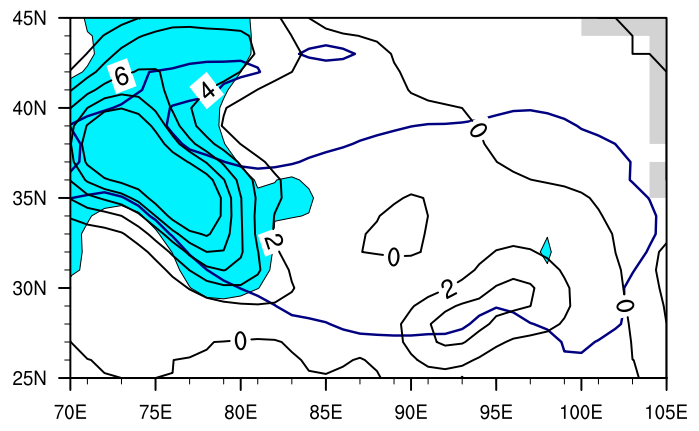

b) Regressed JJA TPSC against May SAMI

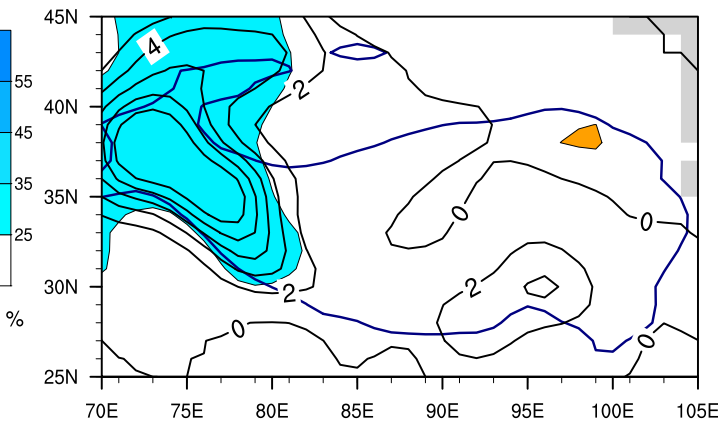

d) IOD removed

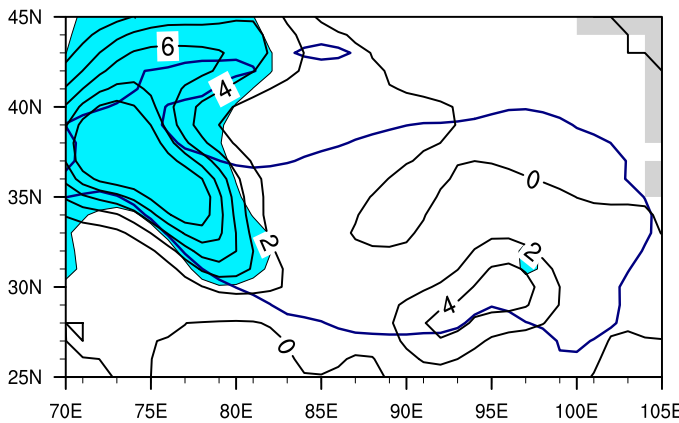

FIG. 1. (a) Long-term average (contours; \%) and standard deviations (color shadings; \%) of the JJA TPSC for the period 1979-2013. (b) The regressed JJA TPSC pattern (contours) against the detrended May SAMI. (c),(d) As in (b), but for the partial regression with the previous DJF ENSO and SON IOD signal removed, respectively. The shadings in (b)-(d) denote the regressed anomalies exceeding $90 \%$ confidence level based on the Student's $t$ test, and this applies to the following figures. The bold blue curves represent the outline of the $\mathrm{TP}$ by the contour line of $3000 \mathrm{~m}$. The snow cover averaged in the red box $\left(30^{\circ}-43^{\circ} \mathrm{N}, 70^{\circ}-83^{\circ} \mathrm{E}\right)$ is defined as the TPSCI.

occupies a relatively narrow area around the TP compared with that in winter, it may exert a more significant influence on the remote climate systems than anticipated. Some researchers have discovered that the TPSC in summer can indirectly contribute to the remote climate anomalies (Wang et al. 2008; Wu et al. 2012) by changing the heterogeneous distribution of the atmospheric heating around the TP (Duan and Wu 2003; Zhao and Chen 2001). Meanwhile, the summer TPSC variability itself also plays a direct role in modulating the downstream climate anomalies. For example, Liu et al. (2014b) indicated that the summer TPSC is prominently positively correlated to the interannual variability of simultaneous precipitation over the mei-yu-baiu area. Wu et al. (2012a) pointed out that the TPSC in summer can modulate the relationship between El Niño-Southern Oscillation (ENSO) and the East Asia summer monsoon (EASM). In addition, summer TPSC also can be notably responsible for the northern China heat wave frequency on decadal-to-interdecadal time scales ( $\mathrm{Wu}$ et al. 2012b), as well as the interannual variations of
Eurasia summer heat waves (Wu et al. 2016a). Hence, the interannual variability of TPSC in the boreal summer should not be overlooked.

What may give rise to the TPSC anomalies on the interannual time scale? Limited studies indicated that the slowly changing low-boundary forcings such as ENSO and the Indian Ocean dipole (IOD) may modulate the TPSC in winter (Shaman and Tziperman 2005; Yuan et al. 2009, 2012). Nevertheless, the factors that may generate the boreal summer interannual variations of TPSC are not quite clear. Considering the great impact of summer TPSC on climate change, it is essential to reveal the potential extra forcing that may contribute to the TPSC interannual variability in summer.

The Southern Hemisphere (SH) annular mode (SAM), also regarded as the Antarctic Oscillation, is the principal mode of $\mathrm{SH}$ extratropical circulation variability (Rogers and Van Loon 1982; Cai and Watterson 2002; Yuan and Yonekura 2011). It is characterized by a zonal symmetric dipolar pattern of pressure or geopotential height anomalies between the subtropical and subpolar 

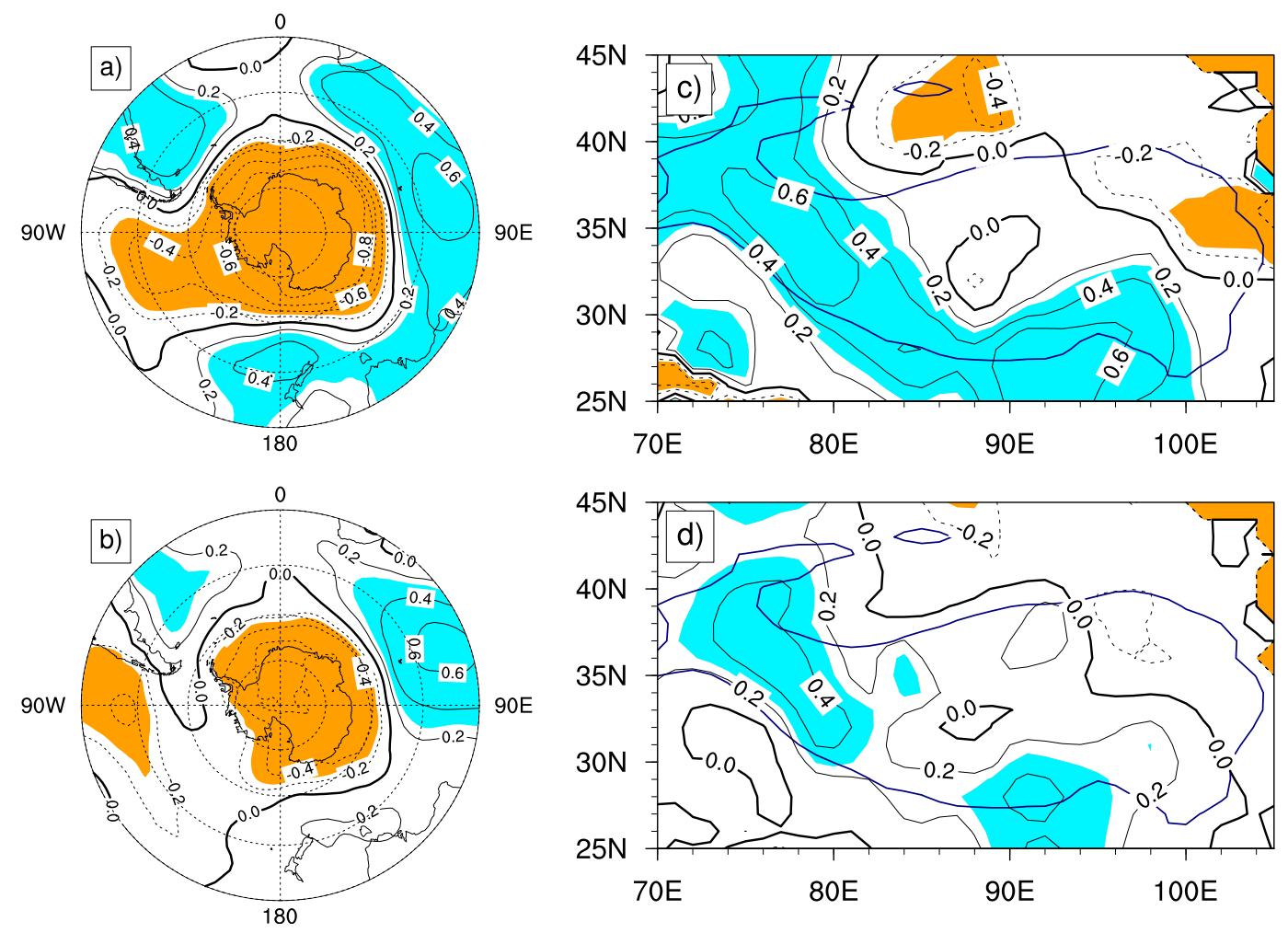

FIG. 2. The leading SVD mode for the detrended (a),(b) May SLP anomalies over the SH $\left(20^{\circ}-90^{\circ} \mathrm{S}, 0^{\circ}-360^{\circ}\right)$ and the detrended (c),(d) JJA TPSC anomalies. (a),(c) The homogeneous correlation patterns, and (b), (d) the heterogeneous correlation patterns. Positive correlation coefficients above the $90 \%$ confidence level are shaded blue; negative is represented by orange. The temporal correlation coefficient between the corresponding expansion coefficients reaches 0.72 above the $99 \%$ confidence level.

regions from the sea level to the stratosphere in the SH on weekly-to-centennial time scales (e.g., Trenberth 1979; Karoly et al. 1996; Gong and Wang 1999; Thompson and Solomon 2002; Marshall 2003; Thompson et al. 2005). Inevitably, the SAM exerts remarkable influences on the precipitation and temperature patterns in most fields of the SH, including South Africa (Reason and Rouault 2005), southern South America (Silvestri and Vera 2003), Australia (Hendon et al. 2007; Cai et al. 2011), and the Antarctic Peninsula (Marshall et al. 2006).

The fingerprint of the SAM may not be restricted to the $\mathrm{SH}$; it can also stretch to the Northern Hemisphere (NH; e.g., Wu et al. 2009b, 2015; Zheng and Li 2012; Liu et al. 2015, 2016). The sea surface temperature (SST), with huge heat storage capacity and a comparatively strong persistence, has been generally considered to play an important "ocean bridge" role in the process of cross-equatorial transmitting of the SAM signal. For instance, Wu et al. (2015) revealed that the South Atlantic-Pacific (SAP) SST anomaly (SSTA) serves as a "recharger" to "prolong" the
SAM influence. Nan and Li (2003) proposed that the Indian Ocean SSTA plays a crucial role in linking the spring SAM and the subsequent-season EASM and the related precipitation (Nan et al. 2009; Zheng et al. 2015). Recently, Dou et al. (2017) further demonstrated that the spring SAM signal can be imprinted into the Indian Ocean and then modulates the early boreal summer Indian summer monsoon rainfall. Moreover, the Atlantic Ocean SSTA also plays a significant role in bridging the spring SAM and the North American summer monsoon (Sun 2010), as well as the West African summer monsoon (Sun et al. 2010). Therefore, the SAM may provide a fresh potential predictability source for climate anomalies in the $\mathrm{NH}$.

Then, can the SAM influence the interannual variations of TPSC in boreal summer? And if so, what is the corresponding physical mechanism? To settle the above issues, the following manuscript is organized as follows: The datasets, model, and methodology are introduced in section 2. The observed relationship between the May SAM and summer TPSC is diagnosed in section 3. In 
a) JJA TPSCI \& May SAMI

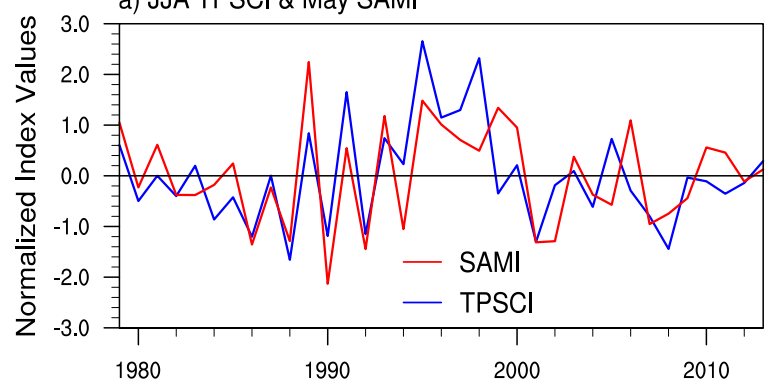

b) TPSCI leadlag correlated with $\operatorname{Dec}(-1)-\operatorname{Sep}(0)$ SAMI

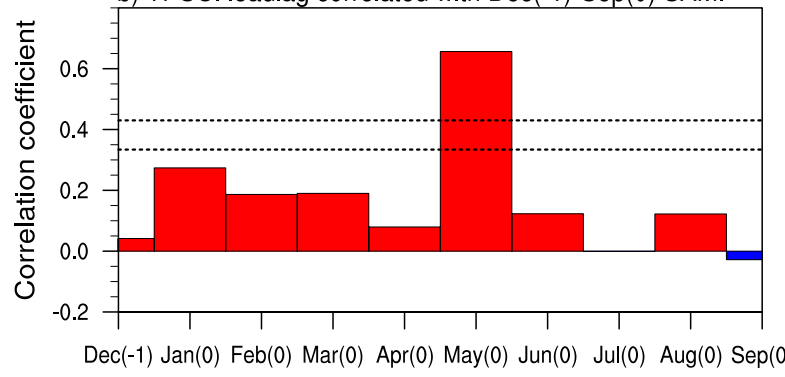

FIG. 3. (a) Time series of the detrended May SAMI (red curve) and the detrended JJA TPSCI (blue curve) for the period 19792013. Their correlation coefficient is 0.66 , beyond the $99 \%$ confidence level. (b) Lead-lag correlations (color bars) between the detrended JJA TPSCI and the detrended SAMI from December $(-1)$ in preceding year through September (0) in the simultaneous year. The dashed horizontal lines represent the $95 \%$ (lower) and $99 \%$ (upper) confidence level, respectively.

section 4, an atmospheric general circulation model (AGCM) and Rossby wave ray tracing method are applied to give us a deeper insight into the mechanisms. In the final section, the main conclusions are summarized and some outstanding issues are presented.

\section{Datasets, model, and methodology}

\section{a. Datasets}

The datasets applied in the present paper include 1) monthly snow-cover area extent data during 1979 2013 taken from the Global Snow Laboratory (Rutgers University; http://climate.rutgers.edu/snowcover; Robinson et al. 1993; Robinson and Frei 2000; Estilow et al. 2015); 2) monthly rainfall data acquired from the Global Precipitation Climatology Project (GPCP) with $2.5^{\circ} \times 2.5^{\circ}$ grid since 1979 (Adler et al. 2003); 3) monthly circulation data, gridded at $1.5^{\circ} \times 1.5^{\circ}$ resolution, provided by the European Centre for Medium-Range Weather Forecasts (ECMWF) interim reanalysis (ERA-Interim) dataset (Dee et al. 2011); 4) monthly SST data from the NOAA improved Extended Reconstructed SST, version 4, (ERSST. v4) with $2^{\circ} \times 2^{\circ}$ resolution (Huang et al. 2015); 5) surface a) May $10 \mathrm{~m}$ winds \& SLP regressed against SAMI

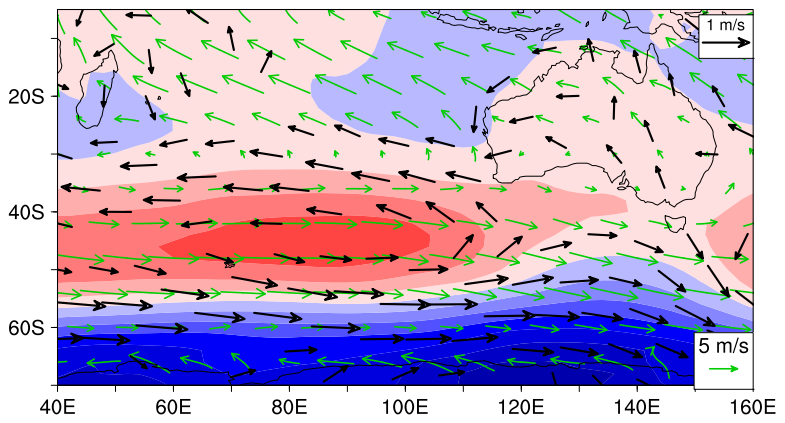

b) Surface current regressed against SAMI

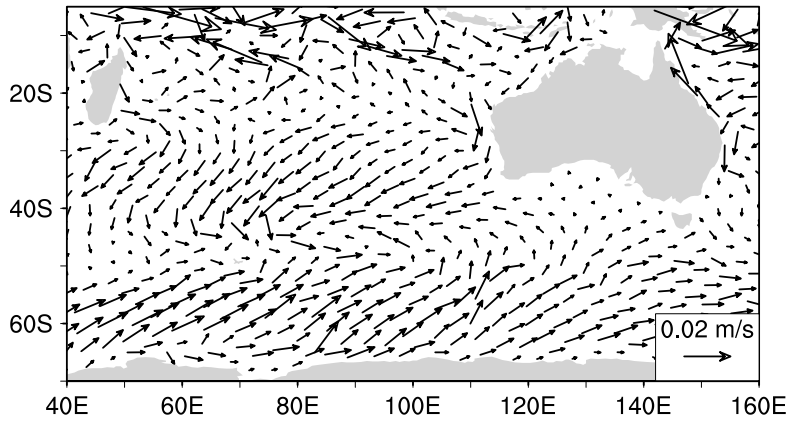

FIG. 4. (a) May 10-m wind anomalies (black vectors; $\mathrm{m} \mathrm{s}^{-1}$ ) and SLP anomalies (color shadings; $\mathrm{Pa}$ ) in the $\mathrm{SH}$ linearly regressed against the detrended May SAMI. Green vectors denote the climatological $10-\mathrm{m}$ wind $\left(\mathrm{m} \mathrm{s}^{-1}\right)$. (b) May ocean surface current anomalies (vectors; $\mathrm{m} \mathrm{s}^{-1}$ ) related to the SAM. The ocean surface current data are taken from GODAS.

heat flux data from the Japanese 55-year Reanalysis (JRA-55) and the ocean surface current data from NCEP Global Ocean Data Assimilation System (GODAS) during 1980-2012 (Behringer et al. 1998); 6) monthly SAM index (SAMI) is designated as the monthly mean difference between the sea level pressure (SLP) anomalies at six stations around midlatitude and six stations near the subpolar region (Marshall 2003), which performs better on the hydroclimate investigation (Ho et al. 2012); The Niño-3.4 index is implied to represent the ENSO variability, that is, the averaged SST over the area $\left(5^{\circ} \mathrm{S}-5^{\circ} \mathrm{N}, 170^{\circ}-120^{\circ} \mathrm{W}\right.$; Trenberth 1997); the index to describe the IOD variability is designated as the SST difference between the western tropical Indian Ocean $\left(10^{\circ} \mathrm{S}-10^{\circ} \mathrm{N}, 50^{\circ}-70^{\circ} \mathrm{E}\right)$ and the eastern tropical Indian Ocean $\left(10^{\circ} \mathrm{S}-0^{\circ}, 90^{\circ}-110^{\circ} \mathrm{E}\right.$; Saji et al. 1999). The period studied in this work is from 1979 to 2013. The summer in this paper indicates the months of June-August (JJA).

\section{b. Model}

Numerical experiments carried out in this work are based on an AGCM model, the fifth generation Max 


\section{Regression between the May SAMI and}

\section{a) Ekman heat flux}

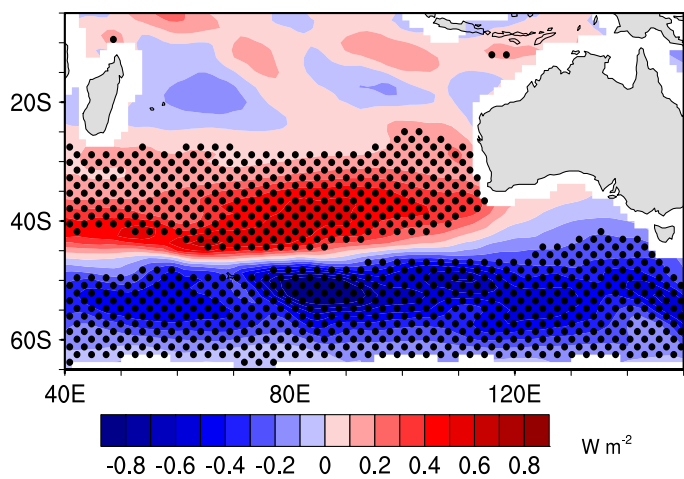

c) Turbulent heat flux

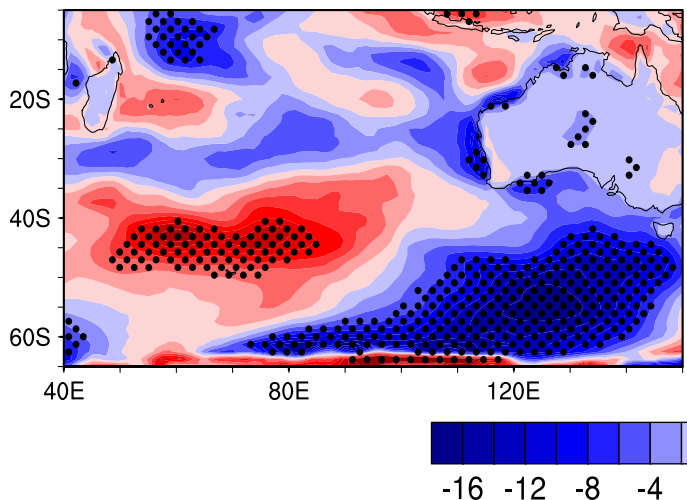

b) Radiative flux

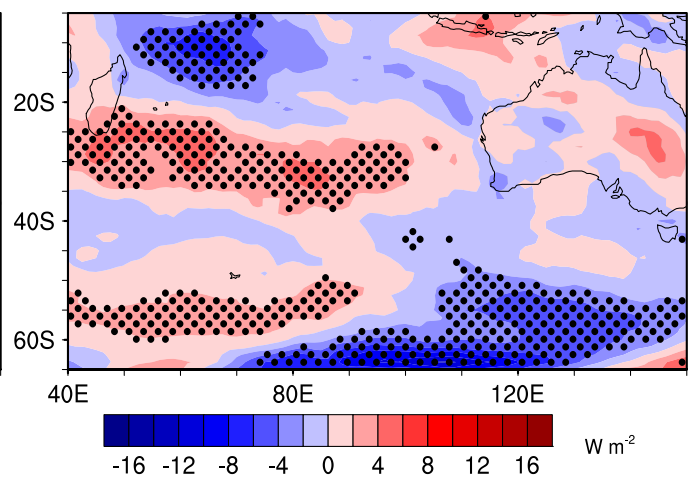

d) Sum heat flux

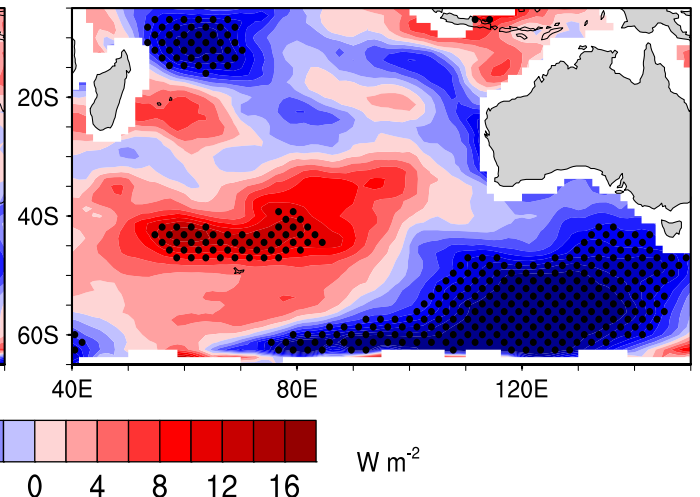

FIG. 5. Regression of the surface (a) Ekman, (b) radiative, (c) turbulent, and (d) net heat fluxes (shadings; $\mathrm{W} \mathrm{m}^{-2}$ ) on the SAMI. Positive values refer to the ocean gaining heat, significant values above $90 \%$ confidence level are dotted. Note that the color bar scales are different.

Planck Institute model in Hamburg (ECHAM5), which is developed on the ECMWF model (Roeckner et al. 2003). The resolution is triangular 63 (T63) and 19 vertical levels. The initial SST forcing fields are provided by Atmospheric Model Intercomparison Project (AMIP) II SST conditions.

\section{c. Methodology}

To emphasize the interannual variability, linear trends of all time series of the aforementioned data have been removed, including circulation and regression fields. A variety of statistical methods were employed to investigate the influence of the May SAM on summer TPSC, such as singular value decomposition (SVD), simultaneous and lead-lag correlation, composite analysis, and regression analysis. To investigate the Rossby wave characteristics of largescale circulation, the eddy streamfunction was calculated by subtracting the zonal-mean component. To analyze the possible wave energy propagation paths in response to the anomalous tropical heating, stationary wave ray tracing theory in horizontally nonuniform basic flow was employed. It has been widely used to trace the Rossby wave train and to explain the atmospheric teleconnection mechanisms (Wu et al. 2016b; Zhou et al. 2018). The detailed theoretical analysis and formula derivation are referred to $\mathrm{Li}$ and $\mathrm{Li}$ (2012), $\mathrm{Li}$ et al. (2015), and Zhao et al. (2015).

\section{Summer TPSC associated with the May SAMI}

Figure 1a displays the spatial distribution of the climatological percentage (contours) and standard deviations (shadings) of the year-to-year variability of summer TPSC during the period 1979-2013. Although snow cover obviously melts over the northeastern TP at lower altitudes during summer, large snow-cover centers are located in its western and southern edges with 


\section{Regression between the May SAMI and}

a) May SST

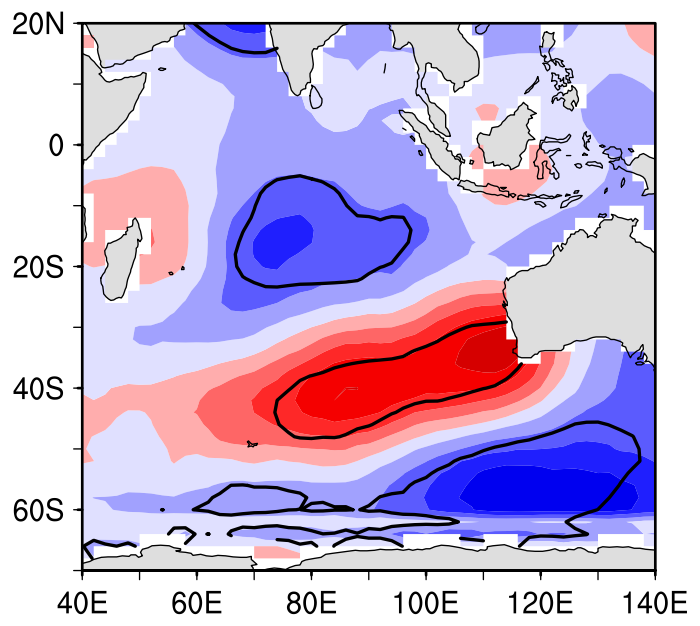

b) JJA SST

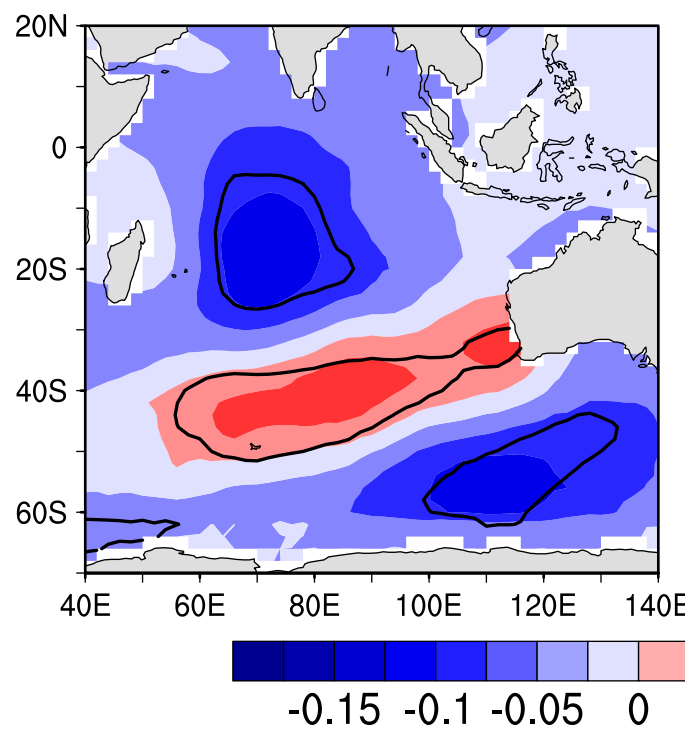

c) May SST (ENSO removed)

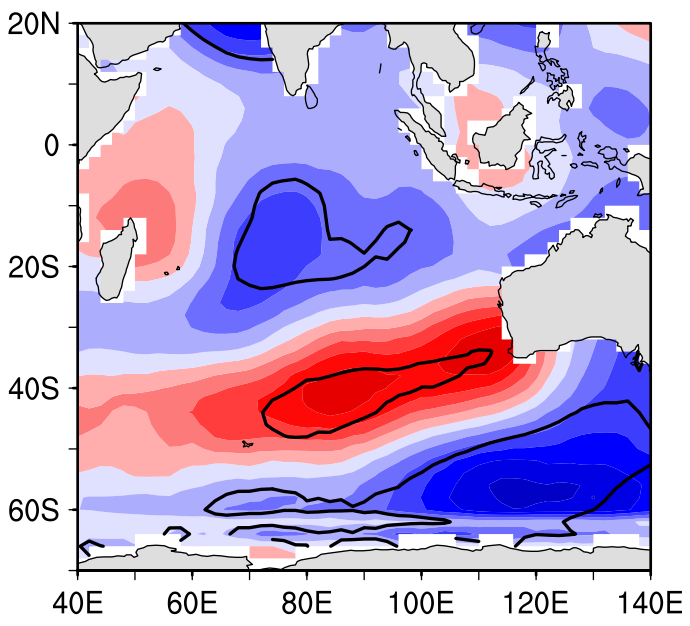

d) JJA SST (ENSO removed)

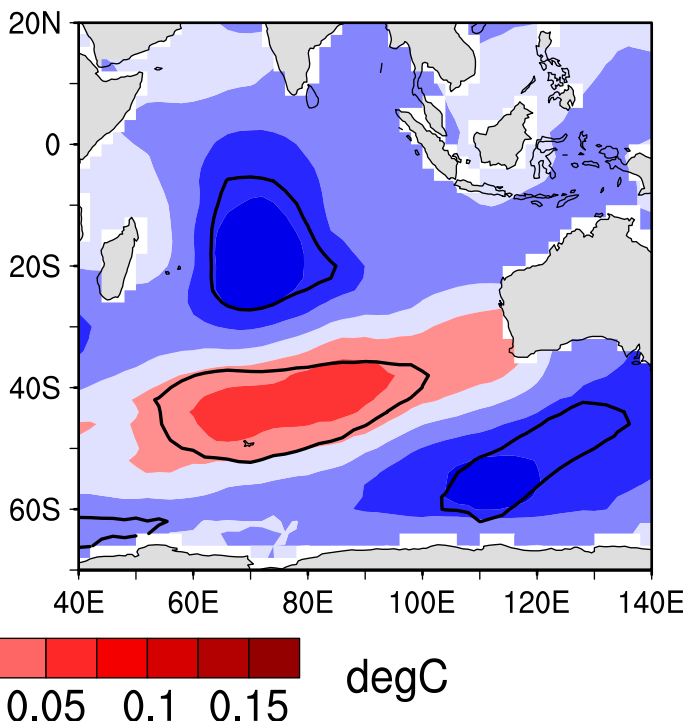

FIG. 6. (a) May and (b) JJA SSTA regressed (shadings; ${ }^{\circ} \mathrm{C}$ ) against the detrended May SAMI. (c),(d) As in (a),(b), but for the partial regression patterns with the DJF ENSO signal removed. The SST anomalies included in the bold black curves exceed the $90 \%$ confidence level. The IOTI is obtained by projecting the regressed SST field in the Indian Ocean $\left(65^{\circ}-5^{\circ} \mathrm{S}, 60^{\circ}-130^{\circ} \mathrm{E}\right)$ onto the normalized SST pattern in the same area.

large mountain ridges. Strong standard deviations centers also occupy the western plateau and southern flank of the TP. Overlapped with the outstanding yearto-year snow-cover changes, large areas of anomalous TPSC regressed against the May SAMI are centered in the western TP and adjoining regions (Fig. 1b). In consideration of ENSO, the IOD effect on the TPSC and the partial-regressed JJA TPSC patterns against the May SAMI are shown in Figs. 1c and 1d. With the previous autumn [September-November (SON)] IOD and winter [December-February (DJF)] ENSO signals eliminated, significant anomalies still dominate over the western TP and the adjacent areas. This implies a strong May SAM is usually associated with more western TPSC in the following season, and vice versa.

To further survey the coupling association between the May SAM and boreal summer TPSC, Fig. 2 displays the first SVD mode of the May SLP anomalies in the 
a) UV\&Z500 correlated with the JJA IOTI

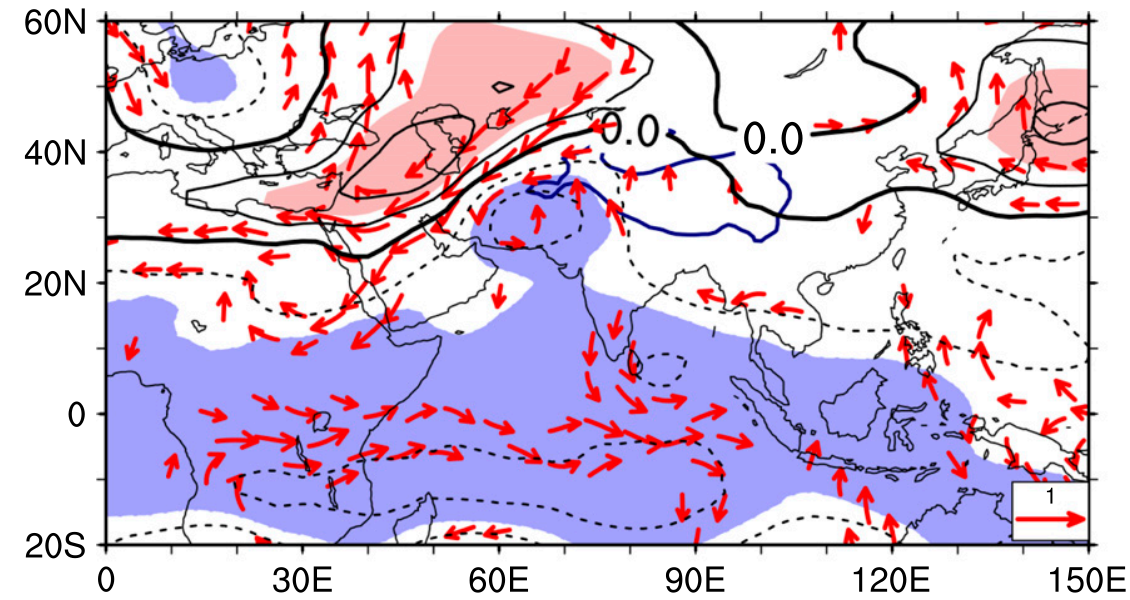

b) ENSO removed

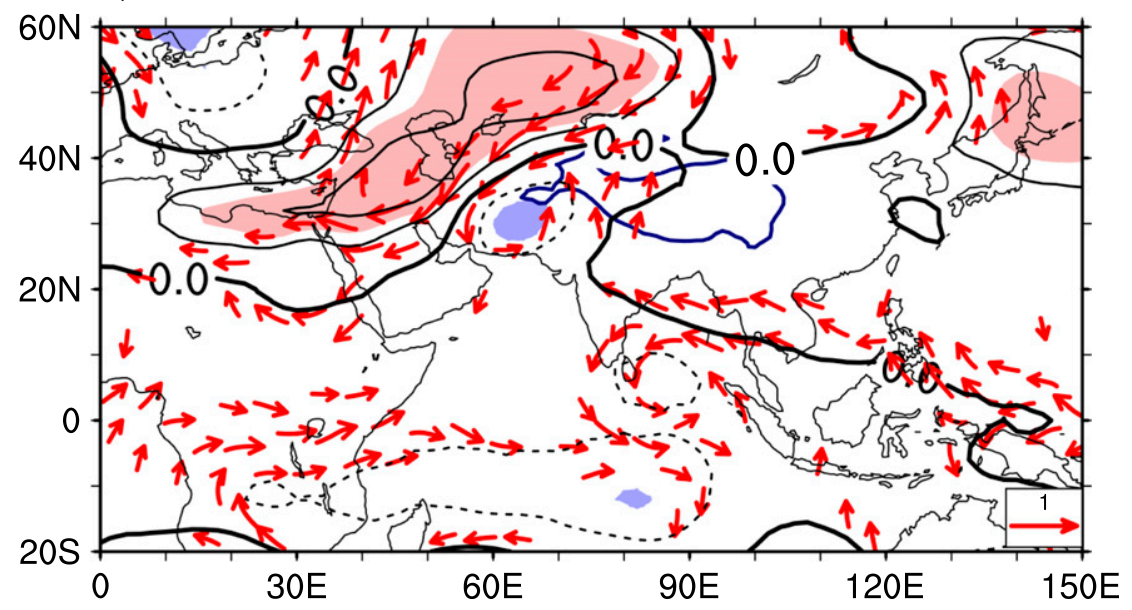

FIG. 7. (a) JJA 500-hPa geopotential height (Z500; shadings) and horizontal winds (UV; vectors) correlated with the detrended IOTI defined in Fig. 5. (b) As in (a), but for the partial correlation with the DJF ENSO removed. The areas with correlation coefficients significant above $90 \%$ confidence level are shaded. The wind vectors plotted exceed the $90 \%$ confidence level.

extratropical $\mathrm{SH}\left(90^{\circ}-20^{\circ} \mathrm{S}, 0^{\circ}-360^{\circ}\right)$ and the following boreal summer's snow-cover anomalies over the TP $\left(25^{\circ}-45^{\circ} \mathrm{N}, 70^{\circ}-105^{\circ} \mathrm{E}\right)$. The first mode interprets $47.3 \%$ of the total covariance. The two time series have a close connection with a correlation coefficient of 0.72 above the $99 \%$ confidence level based on the Student's $t$ test. The left homogeneous correlation pattern reflects a seesaw structure with negative SLP over the polar region and a positive belt over the midlatitude in the SH (Fig. 2a), which indicates a strong SAM phase as recorded by Thompson and Wallace (2000) and Thompson et al. (2000). Correspondingly, the snow cover over the western plateau shows a monosign pattern (Fig. 2c). The right heterogeneous correlation pattern manifests such that the most significant positive anomalies dominate over the western TP and surrounding regions when the May SAM is in its positive polarity (Figs. 2b,d). Combined with the result in Fig. 1, we can infer that the May SAM may noticeably contribute to the variability of western TPSC in the following boreal summer.

To quantitatively describe the western TPSC variability, a JJA TPSC index (TPSCI) is defined as the averaged snow cover in the red box in Fig. $1 \mathrm{a}\left(30^{\circ}-43^{\circ} \mathrm{N}\right.$, $\left.70^{\circ}-83^{\circ} \mathrm{E}\right)$. Figure $3 \mathrm{a}$ shows the temporal variations of the May SAMI and the JJA TPSCI from 1979 to 2013. The TPSCI is closely related to the May SAMI with the correlation coefficient reaching 0.66 beyond the $99 \%$ confidence level. They show a prominent inphase relationship, particularly during the period of 


\section{Regressed JJA wind against IOTI}

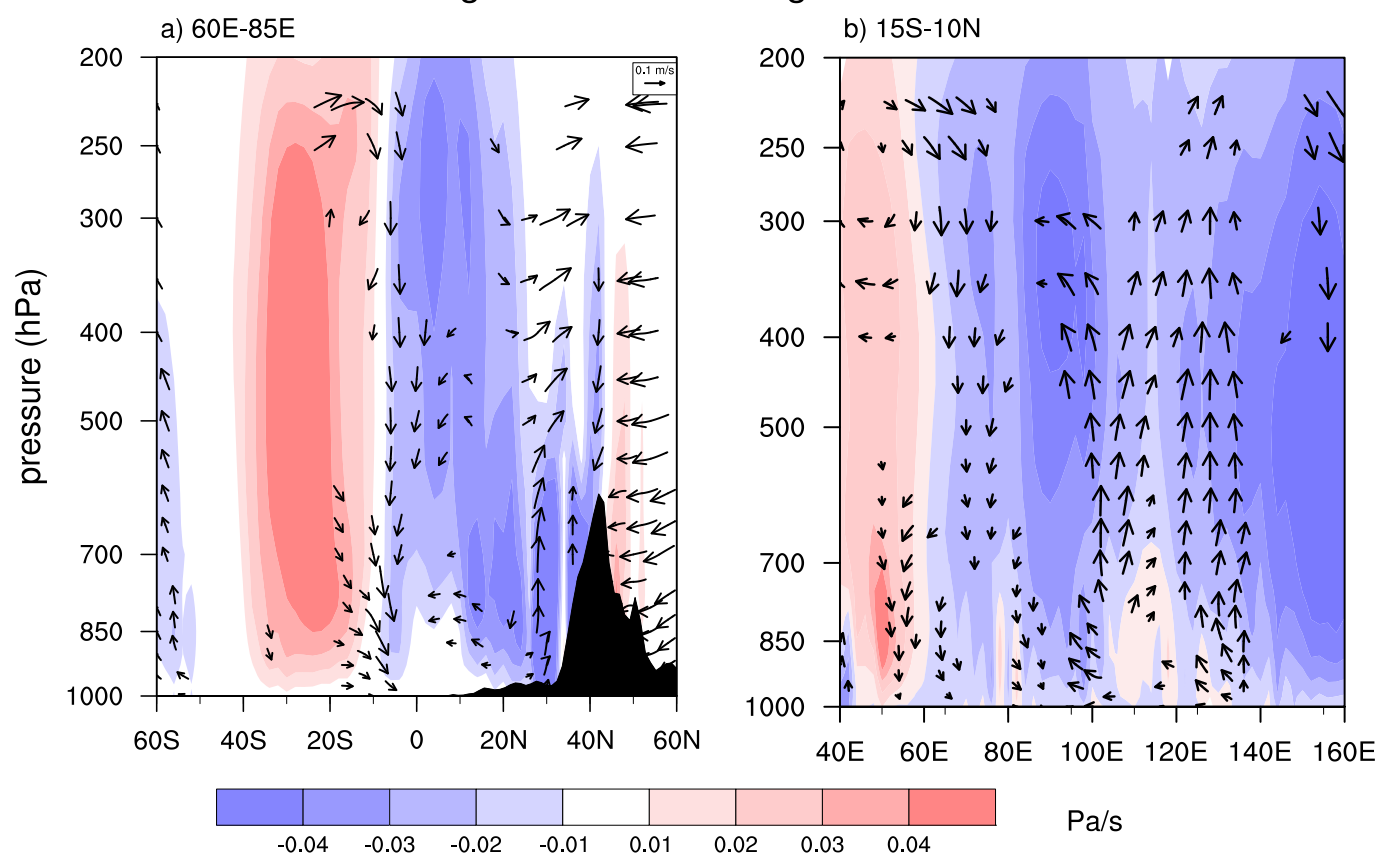

FIG. 8. (a) JJA meridional circulation (vectors; $\left.\mathrm{m} \mathrm{s}^{-1}\right)$ averaged over the Indian Ocean $\left(60^{\circ}-85^{\circ} \mathrm{E}\right)$ and (b) zonalvertical circulation (vectors; $\left.\mathrm{m} \mathrm{s}^{-1}\right)$ averaged over tropics $\left(15^{\circ} \mathrm{S}-10^{\circ} \mathrm{N}\right)$ regressed against the detrended IOTI. The vectors represent the vertical and meridional components in (a) and vertical and zonal components in (b). The shaded areas denote the climatological mean of vertical velocity $\left(\mathrm{Pa} \mathrm{s}^{-1}\right)$. The vectors are the regression above $90 \%$ confidence level.

1988-95. Figure 3b displays the lead-lag correlations map between the JJA TPSCI and the SAMI time series from December $(-1)$ to September $(0)$. Here " -1 " represents the previous year and " 0 " denotes the coinstantaneous year. Though the SAM provides precursory conditions from the preceding December to July, only the May SAMI is significantly related to the JJA western TPSC.

The above analysis indicates that the positive relationship between the May SAM and boreal summer TPSC interannual variability is statistically robust. However, as the intrinsic feature of the atmosphere, the SAM itself is short of sustainability (Wu et al. 2009a,b). How can the preceding May SAM signal propagate from the $\mathrm{SH}$ into the $\mathrm{NH}$ and then affect the TPSC variability in the following season?

\section{Physical mechanisms}

\section{a. The "ocean bridge" role of SSTA}

It is widely considered that the slowly varying lowboundary forcing such as a SSTA with strong heat memory capability can increase the persistence of the atmosphere signature (Sen Gupta and England 2006,
2007). In view of this, we speculate that the SSTA might play an "ocean bridge" role in extending the SAM influence and then affect the remote climate anomalies. The strong surface-wind signal related to the SAM can influence the ocean surface temperature through the surface currents and air-sea heat fluxes. The cloud associated with the SAM can also affect the radiative flux to the ocean (Hall and Visbeck 2002; Verdy et al. 2006; Sallée et al. 2010). Thus we have investigated the ocean currents and surface heat fluxes associated with the SAM to illuminate their role in the generation of SST anomalies.

First, the overlying atmospheric circulation associated with the May SAM has been examined. As shown in Fig. 4a, the strong SAM phase is characterized by a seesaw pattern with high pressure in midlatitudes and low pressure anomalies in high latitudes over the south Indian Ocean. Correspondingly, intensive westerly flows prevail over high latitudes and easterly winds over midlatitudes (black vectors), which will change the climate background states. Because of a balance between the Coriolis force and the drags generated by the wind and the water, the westerly surface winds over high latitudes drive Ekman drift to the north, resulting in the northward flow, while easterlies over 
a) UV1000 \& SLP correlated with the JJA IOTI

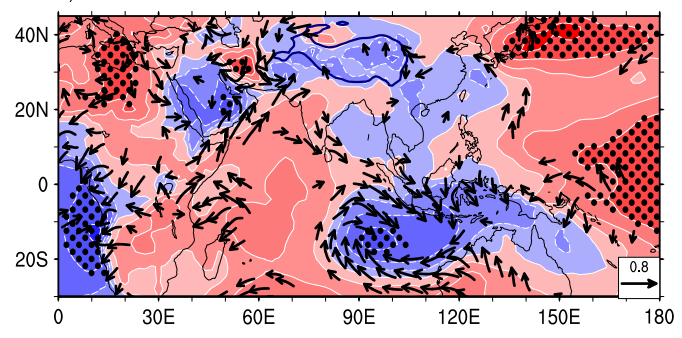

b) VELP200 \& $1000 \mathrm{hPa}$ Divergent wind correlated with IOTI

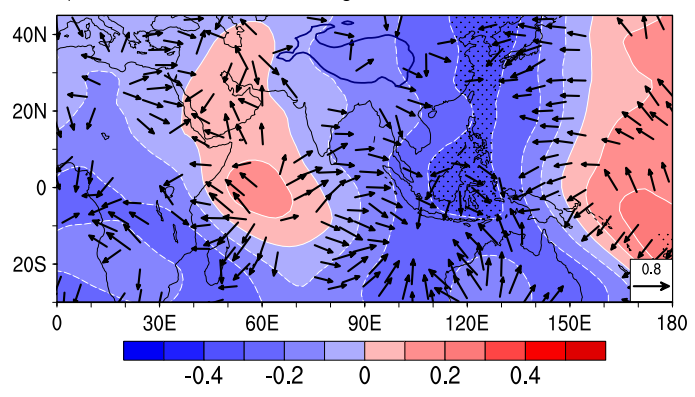

c) UV1000 \& SLP response in ECHAM5

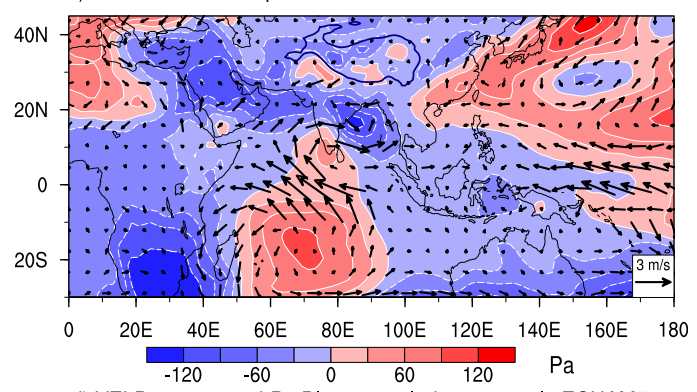

d) VELP200 \& $1000 \mathrm{hPa}$ Divergent wind response in ECHAM5

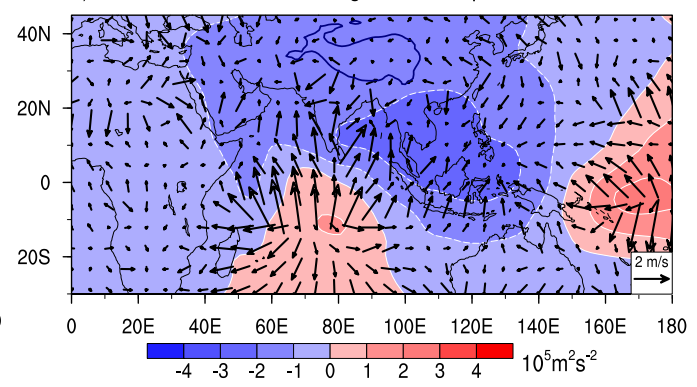

FIG. 9. (a) JJA 1000-hPa horizontal winds (UV1000; vectors) and SLP (shadings), (b) 200-hPa velocity potential (VELP200; shadings) and 1000-hPa divergent winds (vectors) correlated with detrended IOTI. The areas with correlation coefficients significant above the $90 \%$ confidence level are shaded. The wind vectors plotted exceed the $90 \%$ confidence level. (c),(d) As in (a),(b), but for the composited differences response to the high and low IOTI forcing in the ECHAM5 model.

midlatitudes actuate Ekman drift to the south, causing southward currents (Fig. 4b). Over the tropical-subtropical south Indian Ocean, surface currents display clockwise movement with divergent surface flow away from $20^{\circ} \mathrm{S}$. This leads to surface flow convergence and downward motions centered on $45^{\circ} \mathrm{S}$, and divergence and upwelling near $20^{\circ}$ and $60^{\circ} \mathrm{S}$ (figure not shown), which may drive cold water accumulated in the subpolar region and subtropics and warm water accumulated in midlatitudes.

To further illuminate the mechanism behind the changes in the ocean temperature related to the SAM, we have inspected the surface heat flux, including the Ekman heat fluxes (heat advection by the anomalous Ekman currents in the upper ocean), net radiation (net longwave + net shortwave), and surface turbulent heat fluxes (latent + sensible heat fluxes) related to the SAM. Ekman flux in the upper ocean was estimated from wind stress and SST field from the reanalysis. Ekman flux = $\rho C_{\rho}\left(U_{\mathrm{ek}} \nabla \mathrm{SST}\right)$, and $U_{\mathrm{ek}}=(1 / \rho f)\left(-\tau^{y}, \tau^{x}\right)$, where $U_{\mathrm{ek}}$ is the Ekman transport, $\tau^{x}$ and $\tau^{y}$ are the zonal and meridional wind stress, $\nabla$ SST is the SST gradient, $f$ is the Coriolis parameter, and $\rho$ and $C_{\rho}$ are the density and specific heat capacity of seawater, respectively.

The Ekman heat transport generally shows a zonal pattern in response to the SAM: significant negative Ekman heat flux anomalies control the subpolar region, but positive anomalies are observed in midlatitudes (Fig. 5a), which favor the formation of cold SST in high latitudes and warm SST in midlatitudes. The negative Ekman heat flux around the subtropical region becomes insignificant, which implies the Ekman transport related to the SAM might be limited to mid-high latitudes. This pattern is in accordance with the associated changes in the overlying flow over the mid-high latitudes mentioned above (Fig. 4). More important, however, is the response of the net radiative (Fig. 5b) and turbulent heat fluxes (Fig. 5c), which acts to warm and cool the surface ocean. Both the net radiative and turbulent heat fluxes anomalies basically exhibit a tripole pattern over the Indian Ocean with significant negative anomalies (negative values indicate the ocean losing heat) over the basin south of the Australian and subtropical region and the positive anomalies over midlatitudes. The intensity of the flux is largely dominated by air-sea flux anomalies with a relatively weaker contribution from the net radiation and Ekman transport (note the color scales are different). Overall, the net heat flux (sum of the above three heat flux; Fig. 5d) associated with the SAM, showing a tripole pattern over the Indian Ocean, plays a substantial role in generating the tripole SSTA (Fig. 6a).

The above results indicate that the May SAM signal can be imprinted into the distinguished meridional Indian 
a) Corr. (IOTI \& JJA Prec.)

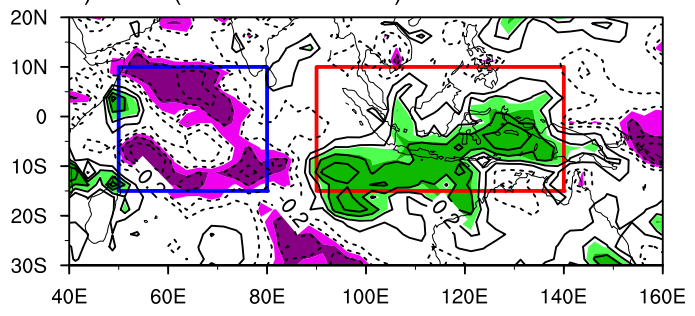

c) Partial-corr. (ENSO removed)

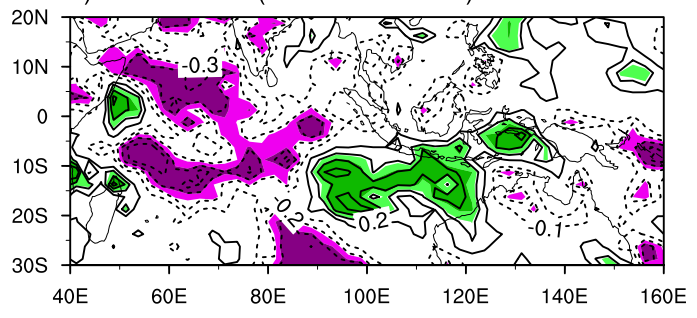

b) Partial-corr. (IOD removed)

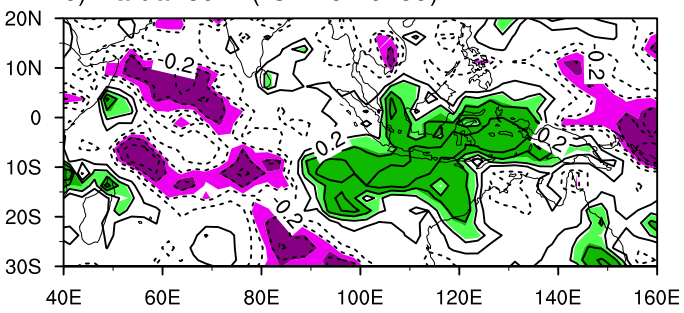

d) Climatology of JJA Prec.

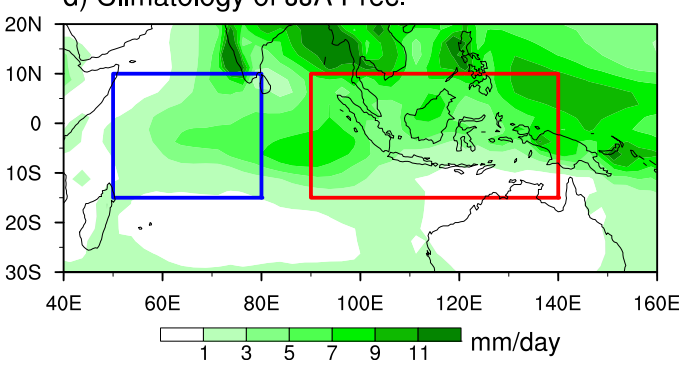

FIG. 10. (a) The correlation pattern (contours; interval 0.1) between the JJA IOTI and JJA precipitation rate. (b),(c) As in (a), but for the partial correlation with the SON IOD and DJF ENSO signal removed. The green (light green) shadings in (a)-(c) denote positive correlation coefficients exceeding the $90 \%$ (85\%) confidence level; blue represents negative. (d) Long-term average (color shadings; $\mathrm{mm} \mathrm{day}^{-1}$ ) of the JJA precipitation rate for the period 1979-2013. A TDRI is defined by the averaged precipitation rate difference in the blue box $\left(15^{\circ} \mathrm{S}-0^{\circ}, 50^{\circ}-80^{\circ} \mathrm{E}\right)$ and red box $\left(15^{\circ} \mathrm{S}-10^{\circ} \mathrm{N}, 90^{\circ}-140^{\circ} \mathrm{E}\right.$; red minus blue $)$.

Ocean tripole (IOT) pattern through the thermodynamic and dynamic processes. This tripole pattern can persist from May to the following season because of the thermal inertia of the oceans (Fig. 6). Meanwhile, with the ENSO signal removed via partial regression, the IOT SSTA patterns are still statistically robust (Figs. 6c,d), which means that the processes described above are independent of ENSO. We have also checked the April SSTA related to the May SAMI; a similar tripole pattern appears in April with fewer significant areas. But if we remove the May SAM signature, the April SSTA cannot persist to the following summer. This implies that the JJA IOT SSTA is indeed closely related to the May SAM (figures not shown).

To quantitatively depict such SAM-related SSTA variability and its impact on TPSC during boreal summer, a simple IOT index (IOTI) is obtained by projecting the regressed SST field in the Indian Ocean $\left(65^{\circ}-5^{\circ} \mathrm{S}\right.$, $60^{\circ}-130^{\circ} \mathrm{E}$ ) onto the normalized SST pattern in the same area. The correlation coefficient between the May SAMI and IOTI reaches 0.63 , exceeding $99.9 \%$ confidence level based on the Student's $t$ test. Such a consistency allows us to interpret the IOT SSTA as the ocean "memory" effect to elongate the May SAM influence. We next inspect the JJA IOTI-related atmosphere circulation around the TP. Figure 7a shows the simultaneous correlation between the JJA IOTI and horizontal winds (vectors) as well as geopotential height (shadings) at $500 \mathrm{hPa}$. A prominent cyclonic circulation associated with a positive IOTI prevails over the western TP, even after the ENSO signal was removed. Figure 8a displays the vertical cross-section between the IOTI and JJA meridional wind section averaged over the western TP $\left(60^{\circ}-85^{\circ} \mathrm{E}\right)$. Enhanced local-scale meridional circulation is triggered with ascending motions prevailing over the western TP. These circulation anomalies related to the IOTI offer dynamic conditions for TPSC anomalies.

The question is how the signature of the IOT SSTA associated with the May SAM can pass through the equator and then induce the atmospheric circulation anomalies over the TP. To solve this issue, we need to clarify the dynamic structures of the JJA circulation pattern related to the IOT SSTA. Figure 9a shows the lower-level circulation anomalies associated with the IOTI. A positive IOT SST pattern with negative SST anomalies in the tropical-subtropical south Indian Ocean is followed by high pressure and low pressure over the western tropical Indian Ocean (TWIO) and the eastern Indian Ocean-Maritime Continent (EIOMC), respectively. This pattern is accompanied by surface divergence over the TWIO and convergence over the EIOMC. It can be further demonstrated in Fig. 9b; significant positive anomalies of $200-\mathrm{hPa}$ velocity potential prevail over the TWIO along with anomalous wind divergence at $1000 \mathrm{hPa}$. Over the EIOMC, the situation is 


\section{JJA wind response in ECHAM5 model}

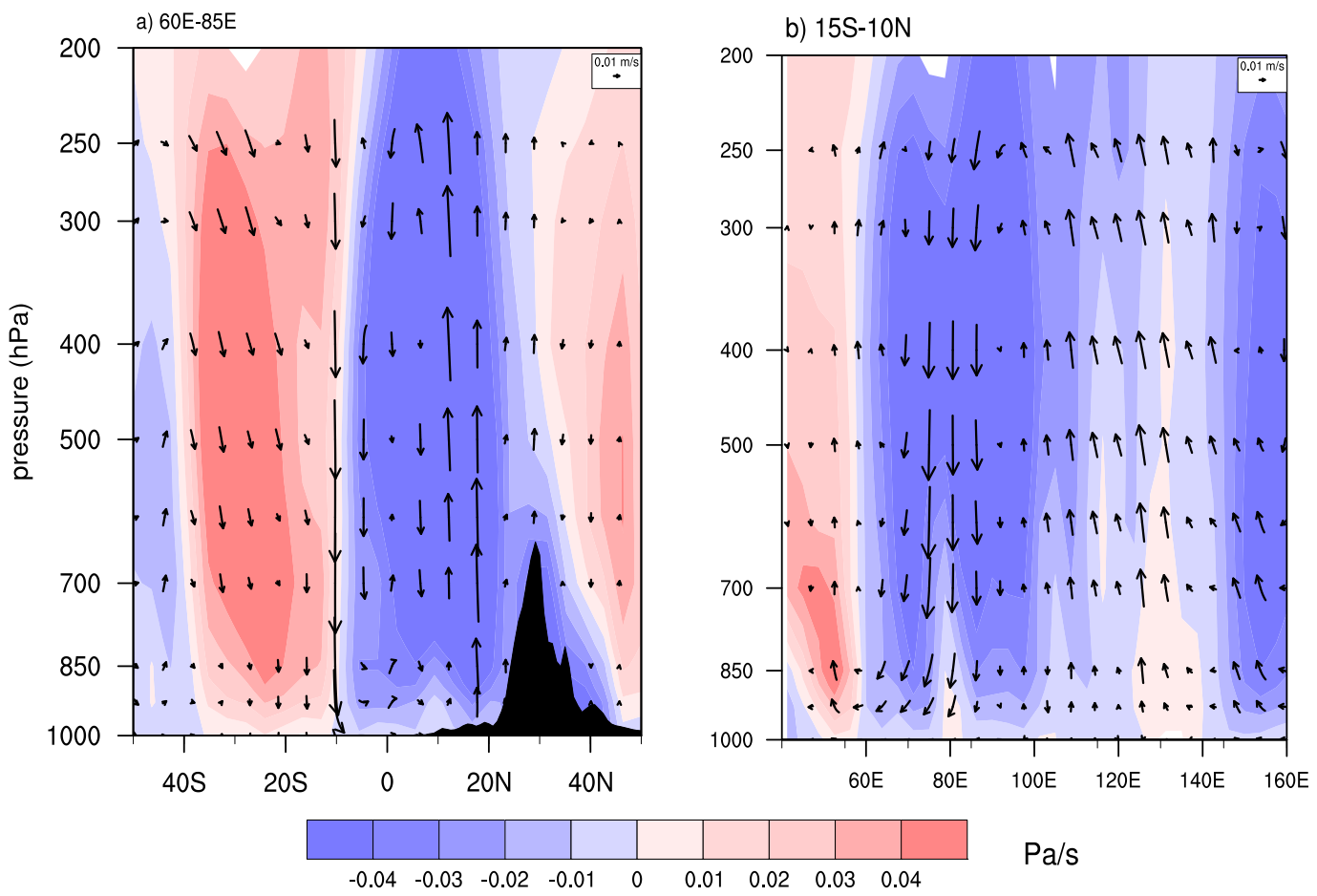

FIG. 11. (a) Composite differences of JJA meridional circulation (vectors; $\mathrm{m} \mathrm{s}^{-1}$ ) averaged over the Indian Ocean $\left(60^{\circ}-85^{\circ} \mathrm{E}\right)$ and (b) zonal-vertical circulation (vectors; $\left.\mathrm{m} \mathrm{s}^{-1}\right)$ averaged over the tropical region $\left(15^{\circ} \mathrm{S}-10^{\circ} \mathrm{N}\right)$ response to the high and low IOTI forcing in the ECHAM5 model. The vectors represent the vertical and meridional components in (a) and vertical and zonal components in (b). The shaded areas denote the climatological mean of vertical velocity $\left(\mathrm{Pa} \mathrm{s}^{-1}\right)$.

just opposite. Consequently, enhanced local-scale zonal circulation is induced with abnormal downward currents (vectors in Fig. 8a) prevailing over the TWIO region $\left(10^{\circ} \mathrm{S}-10^{\circ} \mathrm{N}\right)$ and upward currents (vectors in Fig. $8 \mathrm{~b}$ ) over the EIOMC $\left(100^{\circ}-140^{\circ} \mathrm{E}\right)$. The situation remains significant after the ESNO effect is excluded (figure not shown). These anomalous circulations associated with the IOTI may lead to an abnormal dipole rainfall pattern with significant positive anomalies in the EIOMC and negative anomalies in the TWIO (Fig. 10a). This rainfall mode still exists after the effect of ENSO and the IOD are removed (Figs. 10b,c).

\section{b. Numerical experiments}

To further examine the atmospheric circulation anomalies forced by the IOTI, three numerical experiments were executed with the ECHAM5 model described in section 2. One was the control run driven by the historical SST; the others were the sensitive runs forced by the IOTI anomalous forcing. To mimic the diabatic heating influence of the SSTA, the composited observational SSTA between the high and low May
SAMI (high minus low) was imposed on the historical SST over the Indian Ocean under the positive sensitive run, while the inverse case was imposed under the negative run. Note that a high (low) SAMI is measured by 0.8 standard deviations. All three tests were integrated for 30 years from 1969 to 1998, and the ensemble mean of the last 20 years was employed for eliminating the model spinup.

The simulated climatological circulation patterns are approximately in conformity with the observation (figure not shown). The simulated results in response to the IOT forcing basically capture the major characteristics mentioned above. The positive IOT forcing excites high pressure anomalies over the TWIO along with positive velocity potential (VELP200) and low pressure in the EIOMC with negative VELP200 (Figs. 9c,d). The negative center of VELP200 over the EIOMC slightly moves to the north compared with the observation. Subsequently, enhanced zonal-vertical circulation is induced with descending anomalies prevailing over the TWIO region and ascending anomalies over the EIOMC (vectors in Fig. 11). These then provide a 
precursory condition for fewer precipitation anomalies over the TWIO and more precipitation over the EIOMC. The numerical experiments further verify that the IOT SSTA can modulate the tropical dipole rainfall variability through changing the tropical zonal-vertical circulation.

According to the analysis above, the IOT SSTA plays an "ocean recharger" role to restore the influence of the SAM and then regulates the tropical dipole rainfall (TDR) mode. However, we mainly focus on how the SAM can affect the circulation around the TP. Does the TDR play a bridging role in this process?

\section{c. The "atmosphere bridge" role of the TDR}

Tropical latent heat release related to rainfall is widely considered to play a crucial role in developing planetary-scale low-frequency disturbances in the extratropical field (Gill 1980; Hoskins et al. 1977; Hoskins and Karoly 1981; Karoly 1989). Namely, the tropical anomalous heating generates an abnormal vorticity source, which triggers Rossby wave propagation that induces teleconnection patterns in the extratropical regions.

Figure 12 shows the JJA eddy streamfunction associated with the tropical dipole rainfall index (TDRI; the difference between the blue and red boxes in Fig. 10d). A Gill-type response can be seen in the lower troposphere with a pair of westward-propagating Rossby cyclonic circulation anomalies over the tropical Indian Ocean and anticyclonic shear flow over the east of the Maritime Continent, the upper troposphere with opposite sign at $250 \mathrm{hPa}$. At midlevels, similar features to the $850 \mathrm{hPa}$ are observed with the locations slightly moving to the west. The most significant cyclonic circulation anomalies around the western TP related to the rainfall occur in the mid-low troposphere.

To further illustrate the extratropical response to the tropical anomalous heating associated with the TDR, the stationary wave ray tracing method mentioned above was applied. Figure 13 presents the stationary wave ray paths of zonal wavenumber 3 in the Indian Ocean and Maritime Continent in different background climate flows. At the upper level, the wave source in the two regions can only spread to the SH. Under the $500-\mathrm{hPa}$ flow, the wave packets initiated in the Indian Ocean are difficult to spread out, while parts of the wave source over the Maritime Continent can spread to the western TP. At the lower troposphere, the wave energies in both the EIOMC and the TWIO can only propagate northward to the NH. The northwestwardpropagating wave energies are trapped by the terrain when they reach the TP, which sets off the perturbation over there and then may transmit this effect into

\section{JJA TDRI correlated with}

a) STRF250 \& winds

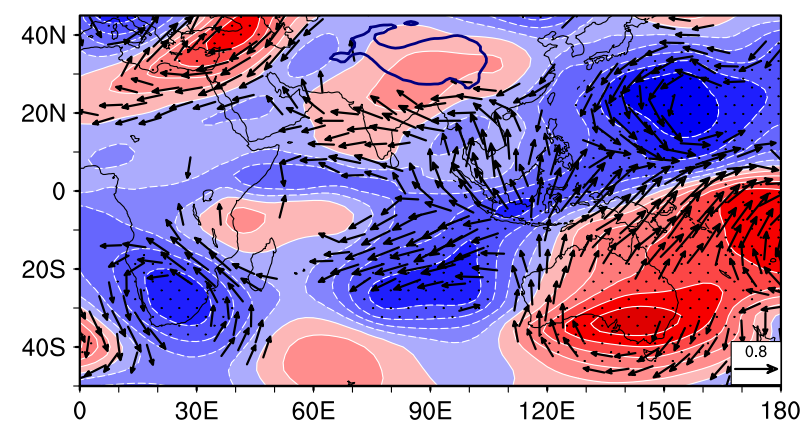

b) STRF500 \& winds

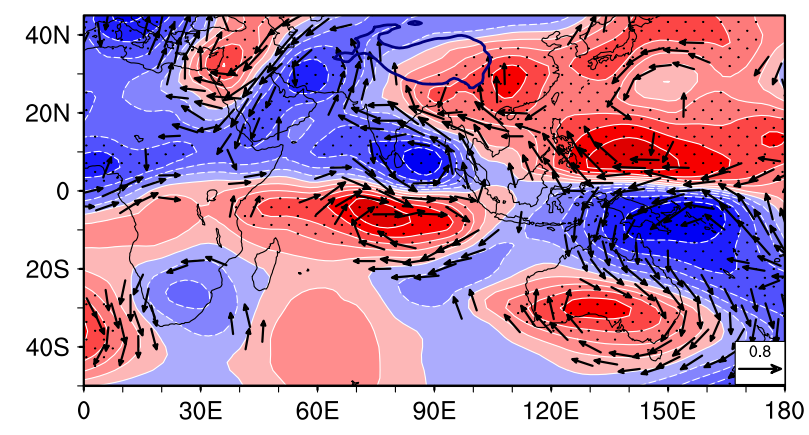

c) STRF850\& winds

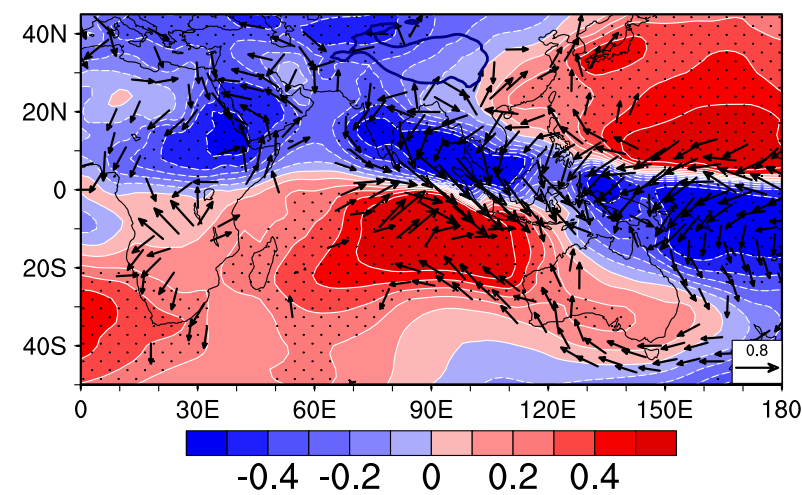

FIG. 12. The eddy streamfunction (shadings) and winds anomalies (vectors) at (a) 200, (b) 500, and (c) $850 \mathrm{hPa}$ correlated to the JJA TDRI. The areas with correlation coefficients significant above the $90 \%$ confidence level are shaded. The wind vectors plotted exceed the $90 \%$ confidence level.

the upper-level atmospheric circulation. As a result, a positive TDRI induces abnormal cyclonic circulation (vectors in Fig. 12) and anomalous updrafts (vectors in Fig. 14) over western TP regions. In addition, the strong May SAM is usually accompanied by negative air temperature anomalies over the western TP (Fig. 15). These conditions may provide advantageous dynamic conditions for more snow cover over the western TP where 

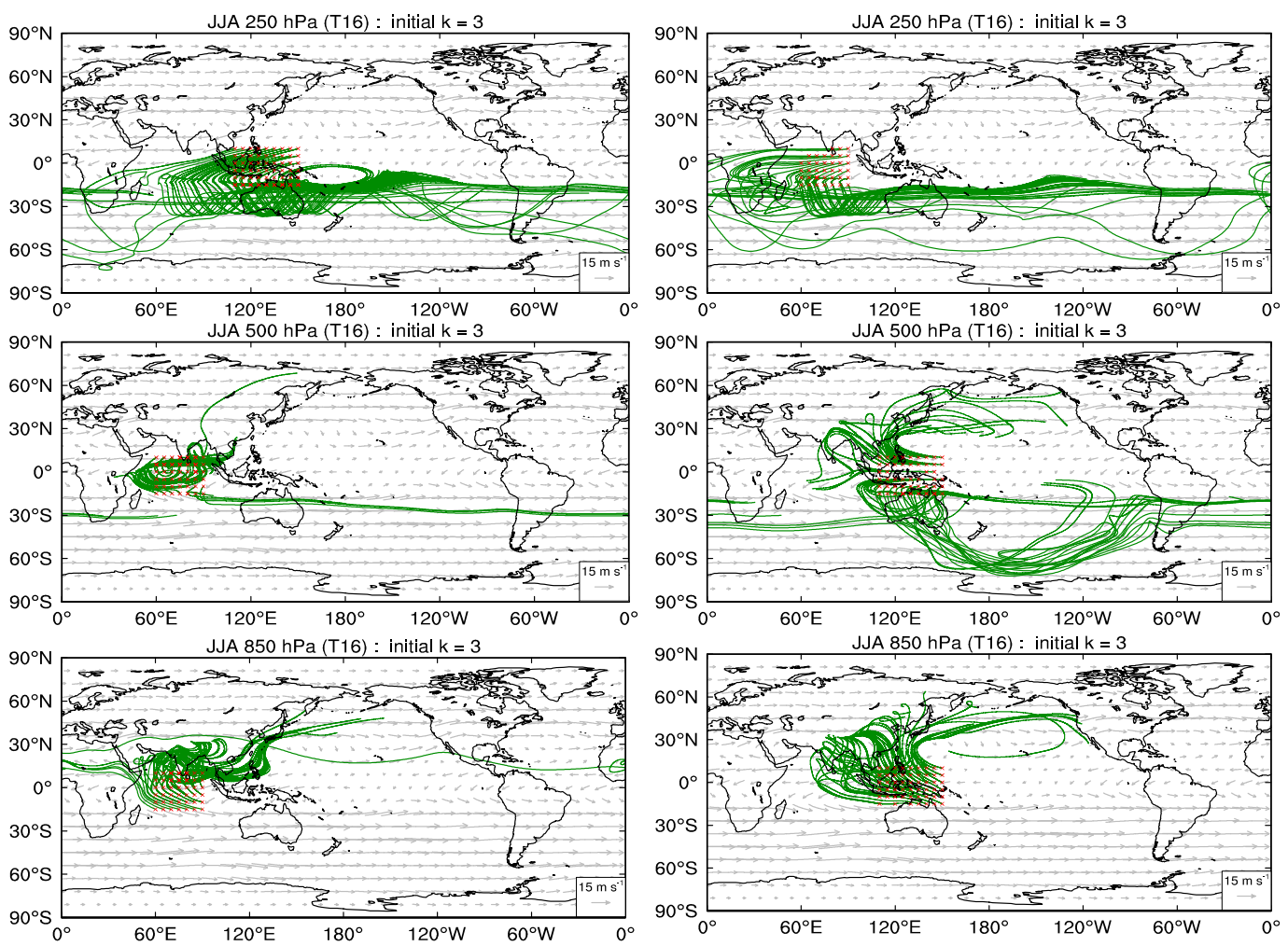

FIG. 13. Stationary Rossby wave ray tracing (curves) of initial zonal wavenumber-3 wave in the JJA flow with the source at $\left(15^{\circ} \mathrm{S}-10^{\circ} \mathrm{N}, 60^{\circ}-90^{\circ} \mathrm{E}\right)$ and $\left(15^{\circ} \mathrm{S}-10^{\circ} \mathrm{N}, 100^{\circ}-150^{\circ} \mathrm{E}\right)$. The red dots indicate the starting points of wave rays in this area. The panels are based on the spherical harmonic smoothing (top) 250-hPa climatological flow, (middle) $500 \mathrm{hPa}$, and (bottom) $850 \mathrm{hPa}$.

there are large mountains. The opposite situation appears during the negative TDRI. Overall, the wave source energy generated by the TDR anomalies can propagate northward into the western TP and, in turn, affect the circulation anomalies over there that regulate the snowcover variability.

From the above analysis, we can conclude that the IOT SSTA plays an "ocean bridge" role to "prolong" the influence of the May SAM and then modulates the precipitation anomalies over the TWIO and the EIOMC, that is, the TDR mode. Subsequently, the TDR mode serves as an "atmosphere bridge" to propagate the wave energy into the western TP and then modulate the interannual variations of TPSC in boreal summer.

\section{Summary and discussion}

The TPSC-induced climatic effects have long been noticed, yet few studies have focused on what may explain the TPSC variability, particularly the boreal summer TPSC. TPSC in summer, exhibiting noticeable year-to-year variability and exerting potential influence on the remote climate, cannot be overlooked (Wu et al. 2012a,b, 2016a; Liu et al. 2014a). In this article, we investigated the potential influence of the previous May SAM on the boreal summer TPSC interannual variability.

Our analyses show that the May SAM has a significant positive correlation with the summer western TPSC, and the relationship is independent of ENSO or the IOD impact. Although the SAM itself may decay rapidly, the thermal inertia of the ocean plays an important bridging role to "elongate" the SAM influence. The evidence presented in the current paper indicates that the May SAM signature can be imprinted onto the IOT SSTA in the Indian Ocean through the thermodynamic and dynamic processes. The positive IOT SSTA pattern, related to the strong May SAM, persists from May to the following season and then inspires abnormal descending motions over the TWIO and ascending currents over the EIOMC. As a response, a positive TDR mode is triggered with positive precipitation over the EIOMC and negative anomalies over the TWIO, and vice versa. Tropical latent heat release associated with the rainfall anomalies can generate teleconnection patterns in the 
a) JJA vertical wind correlatd with TDRI

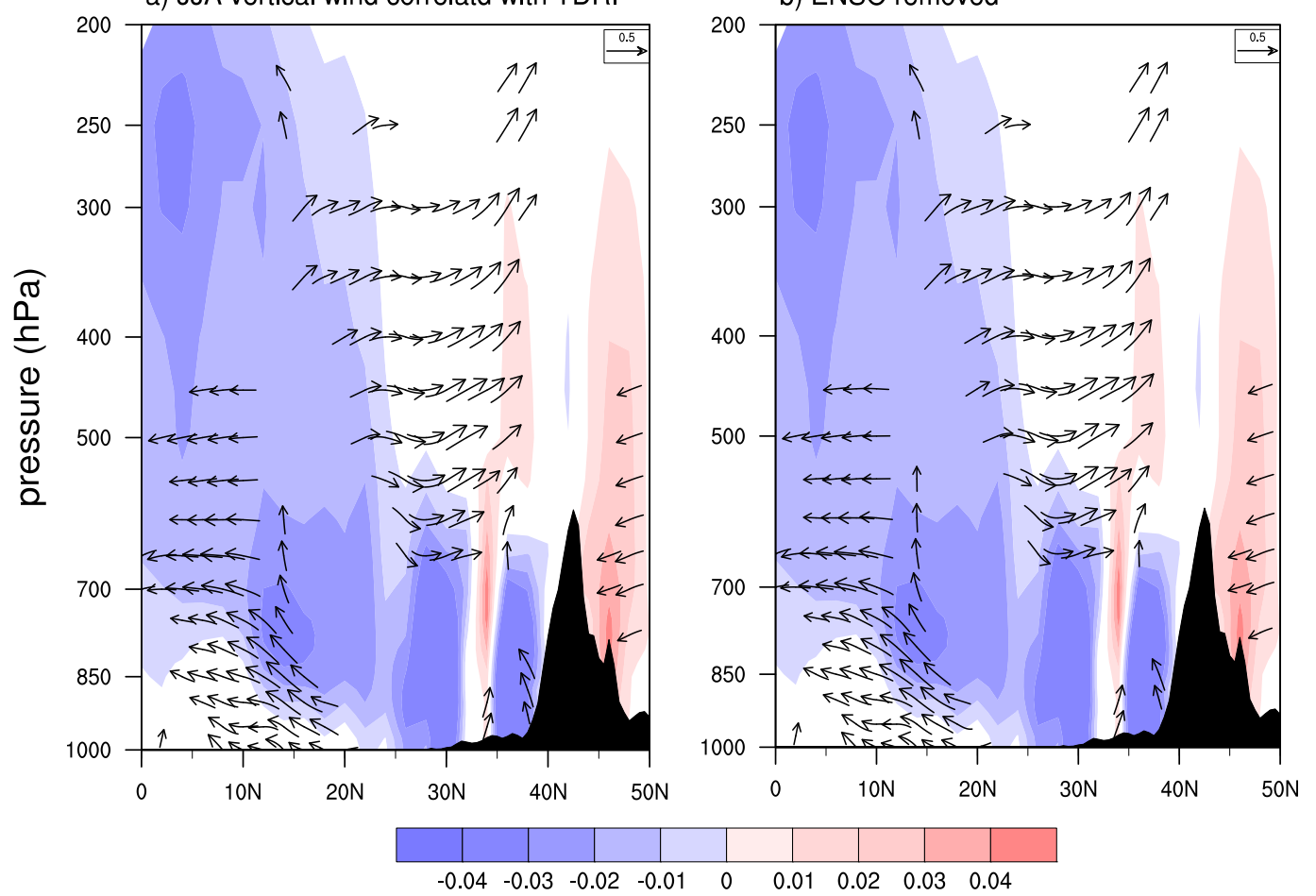

FIG. 14. (a) JJA meridional circulation (vectors) averaged over the western $\mathrm{TP}\left(60^{\circ}-85^{\circ} \mathrm{E}\right)$, correlated with the detrended TDRI. (b) As in (a), but for the partial correlation with DJF ENSO removed. The vectors represent the vertical and meridional components exceeding the $90 \%$ confidence level. The blue and red shaded areas denote the climatological mean of vertical velocity $\left(\mathrm{Pa} \mathrm{s}^{-1}\right)$. Black shadings represent the mean height of the terrain $\left(60^{\circ}-85^{\circ} \mathrm{E}\right)$.

extratropical regions (Hoskins and Karoly 1981). The results from the stationary wave ray tracing analysis indicate that the wave energy propagation related to the positive (or negative) TDR mode can extend into the western TP and then modulate the circulation over there, providing dynamical circumstance to the more (or less) western TPSC. Our conclusion suggests that the May SAM may provide another predictability source for the NH climate and offers additional insight into the interaction between the Northern and Southern Hemispheres.

This work proposes that the May SAM signal can be imprinted into the meridional IOT SSTA through air-sea interaction. In other months, can the SAM arouse a similar SSTA pattern? Besides, a zonal dipole SSTA pattern associated with the May SAM also exists in the SAP areas, which is similar to Fig. 4 in the work of Wu et al. (2015). As the meridional seesaw phenomenon between high and low latitudes, how can the SAM anomalies induce the zonal dipole SSTA pattern? These are still outstanding issues that need further investigation.

It also needs to be pointed out that the monthly SST data employed in this work are derived from the improved ERSST.v4, which is revised based on the ERSST.v3 (Huang et al. 2015). The observational analysis indicates that the May SAM is followed by a meridional tripole SSTA mode in the Indian Ocean. However, if the ERSST.v3 data are applied, a dipole SSTA pattern rather than a tripole SSTA mode associated with the May SAM appears in the Indian Ocean (Fig. 4; Dou et al. 2017). Compared with ERSST.v4, ERSST.v3 may be unable to capture the SSTA in SH high latitudes; this may need to be noted in further studies.

Acknowledgments. The authors are grateful to Prof. Jianping Li, Dr. Yanjie Li, and Dr. Sen Zhao for making the Rossby wave racing code readily available and the anonymous reviewers for their constructive comments, which helped improve the quality of the manuscript. Thanks to Rutgers University Global Snow Lab for providing snow-cover data. This work is jointly supported by the National Natural Science Foundation of China (NSFC; Grants 91637312, 91437216, and 41575075), the Ministry of Science and Technology of China (Grants 2016YFA0601801, 2015CB453201, 
a) JJA temprature correlatd with May SAMI

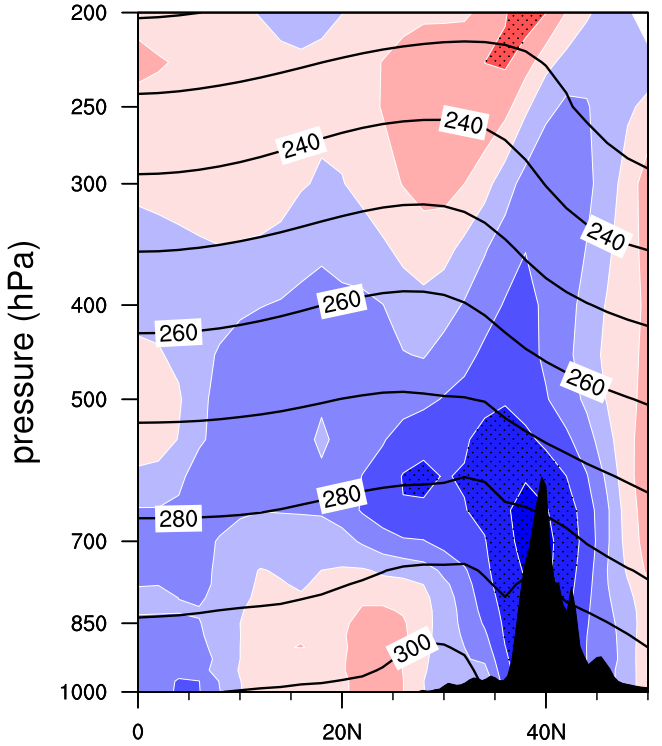

b) ENSO removed

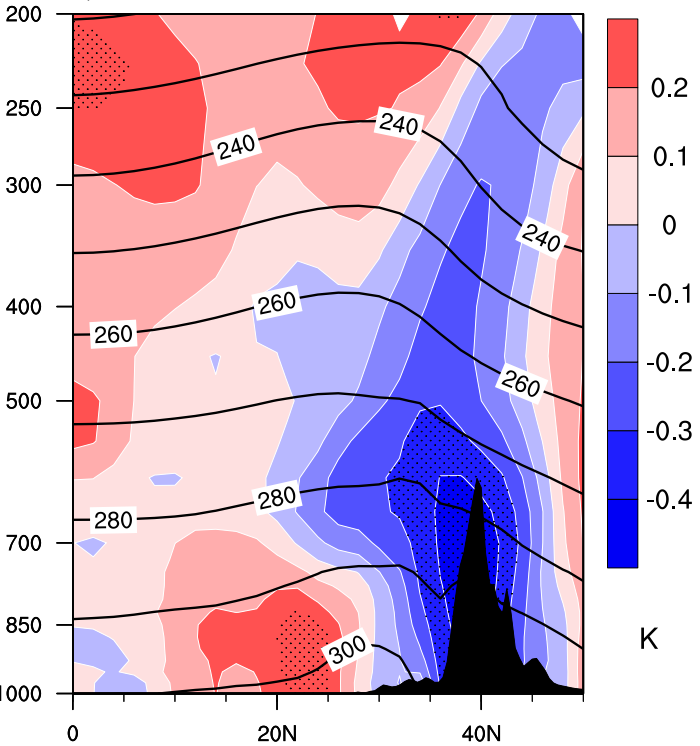

FIG. 15. (a) JJA air temperature (shading) averaged over the western TP $\left(60^{\circ}-85^{\circ} \mathrm{E}\right)$, correlated with the detrended May SAMI. (b) As in (a), but for the partial correlation with DJF ENSO removed. The dotted areas exceed the $90 \%$ confidence level. Contours denote the climatological mean of JJA air temperature $(\mathrm{K})$ averaged over the western TP. Black shadings represent the mean height of the terrain $\left(60^{\circ}-85^{\circ} \mathrm{E}\right)$.

2015CB953904, and 2013CB430202), the Innovation Project of Jiangsu Province (Grant KYLX16_0929), and China Scholarship Council.

\section{REFERENCES}

Adler, R. F., and Coauthors, 2003: The version-2 Global Precipitation Climatology Project (GPCP) monthly precipitation analysis (1979-present). J. Hydrometeor., 4, 1147-1167, https://doi.org/10.1175/1525-7541(2003)004<1147: TVGPCP $>2.0 . \mathrm{CO} ; 2$.

Bamzai, A. S., and J. Shukla, 1999: Relation between Eurasian snow cover, snow depth, and the Indian summer monsoon: An observational study. J. Climate, 12, 3117-3132, https://doi.org/ 10.1175/1520-0442(1999)012<3117:RBESCS $>2.0 . C O ; 2$.

- , and L. Marx, 2000: COLA AGCM simulation of the effect of anomalous spring snow over Eurasia on the Indian summer monsoon. Quart. J. Roy. Meteor. Soc., 126, 2575-2584, https:// doi.org/10.1002/qj.49712656811.

Barnett, T. P., L. Dümenil, U. Schlese, and E. Roeckner, 1988: The effect of Eurasian snow cover on global climate. Science, 239, 504-507, https://doi.org/10.1126/science.239.4839.504.

$[, \ldots, \ldots, \ldots$, and M. Latif, 1989: The effect of Eurasian snow cover on regional and global climate variations. J. Atmos. Sci. 46, 661-686, https://doi.org/10.1175/1520-0469(1989)046<0661: TEOESC $>2.0 . \mathrm{CO} ; 2$.

Behringer, D. W., M. Ji, and A. Leetmaa, 1998: An improved coupled model for ENSO prediction and implications for ocean initialization. Part I: The ocean data assimilation system. Mon. Wea. Rev., 126, 1013-1021, https://doi.org/10.1175/ 1520-0493(1998)126<1013:AICMFE > 2.0.CO;2.

Cai, W., and I. G. Watterson, 2002: Modes of interannual variability of the Southern Hemisphere circulation simulated by the CSIRO climate model. J. Climate, 15, 1159-1174, https://doi.org/ 10.1175/1520-0442(2002)015<1159:MOIVOT>2.0.CO;2.

, P. van Rensch, S. Borlace, and T. Cowan, 2011: Does the southern annular mode contribute to the persistence of the multidecade-long drought over southwest Western Australia? Geophys. Res. Lett., 38, L14712, https://doi.org/10.1029/ 2011 GL047943.

Cohen, J., and D. Rind, 1991: The effect of snow cover on the climate. J. Climate, 4, 689-706, https://doi.org/10.1175/ 1520-0442(1991)004<0689:TEOSCO >2.0.CO;2.

Dee, D. P., and Coauthors, 2011: The ERA-Interim reanalysis: Configuration and performance of the data assimilation system. Quart. J. Roy. Meteor. Soc., 137, 553-597, https://doi.org/ 10.1002/qj.828.

Dou, J., Z. Wu, and Y. Zhou, 2017: Potential impact of the May Southern Hemisphere annular mode on the Indian summer monsoon rainfall. Climate Dyn., 49, 1257-1269, https://doi.org/ 10.1007/s00382-016-3380-4.

Duan, A., and G. Wu, 2003: The main spatial heating patterns over the Tibetan Plateau in July and the corresponding distributions of circulation and precipitation over eastern Asia. Acta Meteor. Sin., 61, 447-456.

Estilow, T. W., A. H. Young, and D. A. Robinson, 2015: A longterm Northern Hemisphere snow cover extent data record for climate studies and monitoring. Earth Syst. Sci. Data, 7, 137142, https://doi.org/10.5194/essd-7-137-2015.

Gill, A. E., 1980: Some simple solutions for heat-induced tropical circulation. Quart. J. Roy. Meteor. Soc., 106, 447-462, https:// doi.org/10.1002/qj.49710644905.

Gong, D., and S. Wang, 1999: Definition of Antarctic oscillation index. Geophys. Res. Lett., 26, 459-462, https://doi.org/ 10.1029/1999GL900003.

Hall, A., and M. Visbeck, 2002: Synchronous variability in the Southern Hemisphere atmosphere, sea ice, and ocean resulting 
from the annular mode. J. Climate, 15, 3043-3057, https://doi.org/ 10.1175/1520-0442(2002)015<3043:SVITSH > 2.0.CO;2.

Hendon, H. H., D. W. J. Thompson, and M. C. Wheeler, 2007: Australian rainfall and surface temperature variations associated with the Southern Hemisphere annular mode. J. Climate, 20, 2452-2467, https://doi.org/10.1175/JCLI4134.1.

Ho, M., A. Kiem, and D. C. Verdon-Kidd, 2012: The southern annular mode: A comparison of indices. Hydrol. Earth Syst. Sci., 16, 967-982, https://doi.org/10.5194/hess-16-967-2012.

Hoskins, B. J., and D. J. Karoly, 1981: The steady linear response of a spherical atmosphere to thermal and orographic forcing. J. Atmos. Sci., 38, 1179-1196, https://doi.org/10.1175/ 1520-0469(1981)038<1179:TSLROA > 2.0.CO;2.

— A. J. Simmons, and D. G. Andrews, 1977: Energy dispersion in a barotropic atmosphere. Quart. J. Roy. Meteor. Soc., 103, 553-567, https://doi.org/10.1002/qj.49710343802.

Huang, B., and Coauthors, 2015: Extended Reconstructed Sea Surface Temperature version 4 (ERSST.v4). Part I: Upgrades and intercomparisons. J. Climate, 28, 911-930, https://doi.org/ 10.1175/JCLI-D-14-00006.1.

Karoly, D. J., 1989: Southern Hemisphere circulation features associated with El Niño-Southern Oscillation events. J. Climate, 2,1239-1252, https://doi.org/10.1175/1520-0442(1989)002<1239: SHCFAW $>2.0 . \mathrm{CO} ; 2$

- P. Hope, and P. D. Jones, 1996: Decadal variations of the Southern Hemisphere circulation. Int. J. Climatol., 16, 723738, https://doi.org/10.1002/(SICI)1097-0088(199607)16: 7<723::AID-JOC54>3.0.CO;2-6.

Li, Y. J., and J. P. Li, 2012: Propagation of planetary waves in the horizontal non-uniform basic flow (in Chinese). Chin. J. Geophys., 55, 361-371.

,,-- F. F. Jin, and S. Zhao, 2015: Interhemispheric propagation of stationary Rossby waves in a horizontally nonuniform background flow. J. Atmos. Sci., 72, 3233-3256, https://doi.org/10.1175/JAS-D-14-0239.1.

Lin, H., and Z. Wu, 2011: Contribution of the autumn Tibetan Plateau snow cover to seasonal prediction of North American winter temperature. J. Climate, 24, 2801-2813, https://doi.org/ 10.1175/2010JCLI3889.1.

— , and — 2012: Contribution of Tibetan Plateau snow cover to the extreme winter conditions of 2009/10. Atmos.-Ocean, 50, 86-94, https://doi.org/10.1080/07055900.2011.649036.

Liu, G., R.-G. Wu, and Y.-Z. Zhang, 2014a: Persistence of snow cover anomalies over the Tibetan Plateau and the implications for forecasting summer precipitation over the meiyu-baiu region. Atmos. Ocean. Sci. Lett., 7, 115-119, https://doi.org/ 10.3878/j.issn.1674-2834.13.0074.

$\ldots, \ldots, \ldots$, and S. Nan, 2014b: The summer snow cover anomaly over the Tibetan Plateau and its association with simultaneous precipitation over the mei-yu-baiu region. Adv. Atmos. Sci., 31, 755-764, https://doi.org/10.1007/ s00376-013-3183-z.

Liu, T., J. Li, and F. Zheng, 2015: Influence of the boreal autumn southern annular mode on winter precipitation over land in the Northern Hemisphere. J. Climate, 28, 8825-8839, https:// doi.org/10.1175/JCLI-D-14-00704.1.

-, J. Feng, X. Wang, and Y. Li, 2016: Cross-seasonal relationship between the boreal autumn SAM and winter precipitation in the Northern Hemisphere in CMIP5. J. Climate, 29, 6617-6636, https://doi.org/10.1175/JCLI-D-15-0708.1.

Luo, H., and M. Yanai, 1984: The large-scale circulation and heat sources over the Tibetan Plateau and surrounding areas during the early summer of 1979. Part II: Heat and moisture budgets. Mon. Wea. Rev., 112, 966-989, https://doi.org/ 10.1175/1520-0493(1984)112<0966:TLSCAH > 2.0.CO;2.

Marshall, G. J., 2003: Trends in the southern annular mode from observations and reanalyses. J. Climate, 16 , 4134-4143, https://doi.org/10.1175/1520-0442(2003)016<4134: TITSAM $>2.0 . \mathrm{CO} ; 2$.

$\longrightarrow$, A. Orr, N. P. M. Van Lipzig, and J. C. King, 2006: The impact of a changing Southern Hemisphere annular mode on Antarctic peninsula summer temperatures. J. Climate, 19, 53885404, https://doi.org/10.1175/JCLI3844.1.

Namias, J., 1985: Some empirical evidence for the influence of snow cover on temperature and precipitation. Mon. Wea. Rev., 113, 1542-1553, https://doi.org/10.1175/1520-0493(1985)113<1542: SEEFTI $>2.0 . \mathrm{CO} ; 2$.

Nan, S., and J. Li, 2003: The relationship between summer precipitation in the Yangtze River valley and boreal spring Southern Hemisphere annular mode. Geophys. Res. Lett., 30, 2266, https://doi.org/10.1029/2003GL018381.

$\_, \ldots$, X. Yuan, and P. Zhao, 2009: Boreal spring Southern Hemisphere annular mode, Indian Ocean sea surface temperature, and East Asian summer monsoon. J. Geophys. Res., 114, D02103, 356-360, https://doi.org/10.1029/2008JD010045.

$\mathrm{Pu}, \mathrm{Z}$., L. Xu, and V. V. Salomonson, 2007: MODIS/Terra observed seasonal variations of snow cover over the Tibetan Plateau. Geophys. Res. Lett., 34, L06706, 137-161, https://doi.org/ 10.1029/2007GL029262.

Qian, Y. F., Y. Q. Zheng, Y. Zhang, and M. Q. Miao, 2003: Responses of China's summer monsoon climate to snow anomaly over the Tibetan Plateau. Int. J. Climatol., 23, 593-613, https:// doi.org/10.1002/joc. 901 .

Reason, C. J. C., and M. Rouault, 2005: Links between the Antarctic Oscillation and winter rainfall over western South Africa. Geophys. Res. Lett., 32, L07705, https://doi.org/10.1029/ 2005 GL022419.

Robinson, D. A., and A. Frei, 2000: Seasonal variability of Northern Hemisphere snow extent using visible satellite data. Prof. Geogr., 52, 307-315, https://doi.org/10.1111/ 0033-0124.00226.

— K. F. Dewey, and R. R. Heim Jr., 1993: Global snow cover monitoring: An update. Bull. Amer. Meteor. Soc., 74, 16891696, https://doi.org/10.1175/1520-0477(1993)074<1689 GSCMAU $>2.0 . \mathrm{CO} ; 2$.

Roeckner, E., and Coauthors, 2003: The atmospheric general circulation model ECHAM5: Part I. Max Planck Institute for Meteorology Rep. 349, 127 pp.

Rogers, J. C., and H. van Loon, 1982: Spatial variability of sea level pressure and $500 \mathrm{mb}$ height anomalies over the Southern Hemisphere. Mon. Wea. Rev., 110, 1375-1392, https://doi.org/ 10.1175/1520-0493(1982)110<1375:SVOSLP $>2.0 . C O ; 2$.

Saji, N. H., B. N. Goswami, P. N. Vinayachandran, and T. Yamagata, 1999: A dipole mode in the tropical Indian Ocean. Nature, 401, 360-363, https://doi.org/10.1038/43854.

Sallée, J. B., K. G. Speer, and S. R. Rintoul, 2010: Zonally asymmetric response of the Southern Ocean mixed-layer depth to the southern annular mode. Nat. Geosci., 3, 273-279, https:// doi.org/10.1038/ngeo812.

Sen Gupta, A., and M. H. England, 2006: Coupled oceanatmosphere-ice response to variations in the southern annular mode. J. Climate, 19, 4457-4486, https://doi.org/10.1175/ JCLI3843.1.

— and - 2007: Coupled ocean-atmosphere feedback in the southern annular mode. J. Climate, 20,3677-3692, https://doi.org/ 10.1175/JCLI4200.1. 
Shaman, J., and E. Tziperman, 2005: The effect of ENSO on Tibetan Plateau snow depth: A stationary wave teleconnection mechanism and implications for the South Asian monsoons. J. Climate, 18, 2067-2079, https://doi.org/10.1175/ JCLI3391.1.

Silvestri, G. E., and C. S. Vera, 2003: Antarctic Oscillation signal on precipitation anomalies over southeastern South America. Geophys. Res. Lett., 30, 2115, https://doi.org/10.1029/ 2003 GL018277.

Sun, J.-Q., 2010: Possible impact of the boreal spring Antarctic Oscillation on the North American summer monsoon. Atmos. Ocean. Sci. Lett., 3, 232-236, https://doi.org/10.1080/ 16742834.2010.11446870.

— - H. Wang, and W. Yuan, 2010: Linkage of the boreal spring Antarctic Oscillation to the West African summer monsoon. J. Meteor. Soc. Japan, 88, 15-28, https://doi.org/10.2151/ jmsj.2010-102.

Thompson, D. W. J., and J. M. Wallace, 2000: Annular modes in the extratropical circulation. Part I: Month-to-month variability. J. Climate, 13, 1000-1016, https://doi.org/10.1175/ 1520-0442(2000)013<1000:AMITEC > 2.0.CO;2.

_ , and S. Solomon, 2002: Interpretation of recent Southern Hemisphere climate change. Science, 296, 895-899, https:// doi.org/10.1126/science.1069270.

_ J. M. Wallace, and G. C. Hegerl, 2000: Annular modes in the extratropical circulation. Part II: Trends. J. Climate, 13, 1018-1036, https://doi.org/10.1175/1520-0442(2000)013<1018: AMITEC $>2.0 . \mathrm{CO} ; 2$.

- M. P. Baldwin, and S. Solomon, 2005: Stratospheretroposphere coupling in the Southern Hemisphere. J. Atmos. Sci., 62, 708-715, https://doi.org/10.1175/JAS-3321.1.

Trenberth, K. E., 1979: Interannual variability of the $500 \mathrm{mb}$ zonal mean flow in the Southern Hemisphere. Mon. Wea. Rev., 107, 1515-1524, https://doi.org/10.1175/1520-0493(1979)107<1515: IVOTMZ $>2.0$.CO;2.

— 1997: The definition of El Niño. Bull. Amer. Meteor. Soc., 78 2771-2777, https://doi.org/10.1175/1520-0477(1997)078<2771: TDOENO $>2.0 . \mathrm{CO} ; 2$

Verdy, A., J. Marshall, and A. Czaja, 2006: Sea surface temperature variability along the path of the Antarctic Circumpolar Current. J. Phys. Oceanogr., 36, 1317-1331, https://doi.org/ 10.1175/JPO2913.1.

Wang, B., Q. Bao, B. Hoskins, G. Wu, and Y. Liu, 2008: Tibetan Plateau warming and precipitation changes in East Asia. Geophys. Res. Lett., 35, L14702, https://doi.org/10.1029/ 2008 GL034330.

Wang, C., K. Yang, Y. Li, D. Wu, and Y. Bo, 2017: Impacts of spatiotemporal anomalies of Tibetan Plateau snow cover on summer precipitation in East China. J. Climate, 30, 885-903, https://doi.org/10.1175/JCLI-D-16-0041.1.

Wu, G., Y. Liu, B. He, Q. Bao, A. Duan, and F.-F. Jin, 2012: Thermal controls on the Asian summer monsoon. Sci. Rep., 2, 404, https://doi.org/10.1038/srep00404.

Wu, Z., B. Wang, J. Li, and F.-F. Jin, 2009a: An empirical seasonal prediction model of the East Asian summer monsoon using ENSO and NAO. J. Geophys. Res., 114, D18120, https://doi.org/ 10.1029/2009JD011733.

_ J. Li, B. Wang, and X. Liu, 2009b: Can the Southern Hemisphere annular mode affect China winter monsoon? J. Geophys. Res., 114, D11107, https://doi.org/10.1029/ 2008JD011501.

,-- Z Z. Jiang, and T. Ma, 2012a: Modulation of the Tibetan Plateau snow cover on the ENSO teleconnections: From the
East Asian summer monsoon perspective. J. Climate, 25, 2481-2489, https://doi.org/10.1175/JCLI-D-11-00135.1.

— Z. Ziang, J. Li, S. Zhong, and L. Wang, 2012b: Possible association of the western Tibetan Plateau snow cover with the decadal to interdecadal variations of northern China heatwave frequency. Climate Dyn., 39, 2393-2402, https://doi.org/ 10.1007/s00382-012-1439-4.

, J. Dou, and H. Lin, 2015: Potential influence of the NovemberDecember Southern Hemisphere annular mode on the East Asian winter precipitation: A new mechanism. Climate Dyn., 44, 1215-1226, https://doi.org/10.1007/s00382-014-2241-2.

—, P. Zhang, H. Chen, and Y. Li, 2016a: Can the Tibetan Plateau snow cover influence the interannual variations of Eurasian heat wave frequency? Climate Dyn., 46, 3405-3417, https://doi.org/10.1007/s00382-015-2775-y.

- X. Li, Y. Li, and Y. Li, 2016b: Potential influence of Arctic sea ice to the interannual variations of East Asian spring precipitation. J. Climate, 29, 2797-2813, https://doi.org/10.1175/ JCLI-D-15-0128.1.

Xiao, Z., and A. Duan, 2016: Impacts of Tibetan Plateau snow cover on the interannual variability of the East Asian summer monsoon. J. Climate, 29, 8495-8514, https://doi.org/10.1175/ JCLI-D-16-0029.1.

Xu, L., and P. Dirmeyer, 2013: Snow-atmosphere coupling strength. Part II: Albedo effect versus hydrological effect. J. Hydrometeor., 14, 404-418, https://doi.org/10.1175/JHM-D-11-0103.1.

Yasunari, T., A. Kitoh, and T. Tokioka, 1991: Local and remote responses to excessive snow mass over Eurasia appearing in the northern spring and summer climate. J. Meteor. Soc. Japan, 69, 473-487, https://doi.org/10.2151/jmsj1965.69.4_473.

Ye, D.-Z., and G.-X. Wu, 1998: The role of the heat source of the Tibetan Plateau in the general circulation. Meteor. Atmos. Phys., 67, 181-198, https://doi.org/10.1007/BF01277509.

Yeh, T. C., S. W. Luo, and P. C. Chu, 1957: The wind structure and heat balance in the lower troposphere over Tibetan Plateau and its surrounding. Acta Meteor. Sin., 28, 108-121.

Yuan, C., T. Tozuka, T. Miyasaka, and T. Yamagata, 2009: Respective influences of IOD and ENSO on the Tibetan snow cover in early winter. Climate Dyn., 33, 509-520, https:// doi.org/10.1007/s00382-008-0495-2.

,$- \ldots$, and T. Yamagata, 2012: IOD influence on the early winter Tibetan Plateau snow cover: Diagnostic analyses and an AGCM simulation. Climate Dyn., 39, 1643-1660, https:// doi.org/10.1007/s00382-011-1204-0.

Yuan, X., and E. Yonekura, 2011: Decadal variability in the Southern Hemisphere. J. Geophys. Res., 116, D19115, https:// doi.org/10.1029/2011JD015673.

Zhang, Y., T. Li, and B. Wang, 2004: Decadal change of the spring snow depth over the Tibetan Plateau: The associated circulation and influence on the East Asian summer monsoon. J. Climate, 17, 2780-2793, https://doi.org/10.1175/ 1520-0442(2004)017<2780:DCOTSS > 2.0.CO;2.

Zhao, H., and G. W. K. Moore, 2004: On the relationship between Tibetan snow cover, the Tibetan Plateau monsoon and the Indian summer monsoon. Geophys. Res. Lett., 31, L14204, https://doi.org/10.1029/2004GL020040.

Zhao, P., and L. Chen, 2001: Climatic features of atmospheric heat source/sink over the Qinghai-Xizang Plateau in 35 years and its relation to rainfall in China. Sci. China, 44D, 858-864, https://doi.org/10.1007/BF02907098.

Z. Zhou, and J. Liu, 2007: Variability of Tibetan spring snow and its associations with the hemispheric extratropical circulation and East Asian summer monsoon rainfall: An 
observational investigation. J. Climate, 20, 3942-3955, https:// doi.org/10.1175/JCLI4205.1.

Zhao, S., J. Li, and Y. Li, 2015: Dynamics of an interhemispheric teleconnection across the critical latitude through a southerly duct during boreal winter. J. Climate, 28, 7437-7456, https:// doi.org/10.1175/JCLI-D-14-00425.1.

Zheng, F., and J. Li, 2012: Impact of preceding boreal winter Southern Hemisphere annular mode on spring precipitation over south China and related mechanism (in Chinese). Chin. J. Geophys., 55, 3542-3557.

, — - L. Wang, F. Xie, and X. Li, 2015: Cross-seasonal influence of the December-February Southern Hemisphere annular mode on March-May meridional circulation and precipitation. J. Climate, 28, 6859-6881, https://doi.org/ 10.1175/JCLI-D-14-00515.1.

Zhou, X., J. Li, F. Xie, R. Ding, Y. Li, S. Zhao, J. Zhang, and Y. Li, 2018: The effects of the Indo-Pacific warm pool on the stratosphere. Climate Dyn., https://doi.org/10.1007/ s00382-017-3584-2, in press.

Zhu, Y., H. Liu, Y. Ding, F. Zhang, and W. Li, 2015: Interdecadal variation of spring snow depth over the Tibetan Plateau and its influence on summer rainfall over East China in the recent 30 years. Int. J. Climatol., 35, 3654-3660, https://doi.org/10.1002/ joc. 4239 . 